\title{
Cornelius de Pauw, Friedrich der Große oder die aufgeklärte Macht der Sinne
}

Anders als im 21. Jahrhundert war Cornelius de Pauw dem Jahrhundert der Aufklärung kein Unbekannter. Er darf zweifellos als einer der unter seinen Zeitgenossen weltweit berühmtesten Repräsentanten der europäischen Aufklärung gelten, der vor allem durch seine Werke über außereuropäische Völker auf sich aufmerksam machte. Seine oftmals im globalen Maßstab Aufsehen erregenden französischsprachigen Schriften wurden in einer nationale Grenzziehungen ganz selbstverständlich überspannenden „République des Lettres“, die man allzu oft und fälschlicherweise auf die Dimensionen Europas begrenzt zu denken geneigt ist, im Kontext jenes „Disputs um die Neue Welt“ gelesen, dessen Geschichte Antonello Gerbi in dem bereits angeführten Standardwerk dargestellt hat. ${ }^{1}$ Ohne de Pauw wäre eine entscheidende Phase dieses Disputs, die Berliner Debatte um die Neue Welt, nicht vorstellbar gewesen. Nehmen wir also diesen illustren Vertreter der europäischen Aufklärung näher unter die Lupe!

Warum ist es bereits ab dem 19. Jahrhundert so still um den holländischen Gelehrten geworden? Die Vielzahl an Polemiken, die de Pauw insbesondere mit seinen Recherches philosophiques sur les Américains, aber auch mit anderen Schriften auslöste, scheint heute längst vergessen, auch wenn man seinen Namen bisweilen noch in flüchtigen Fußnoten oder beiläufigen Nebensätzen findet. Ein Blick auf die internationale Forschungslandschaft zeigt, dass es kaum neuere Publikationen zu den Arbeiten des 1739 in Amsterdam geborenen und 1799 in Xanten verstorbenen Philosophen, geschweige denn ausgedehntere Monographien gibt, die sein gesamtes philosophisches Oeuvre untersuchen würden. ${ }^{2}$ Es ist ruhig, ja verdächtig ruhig geworden um den Mann, der einst die Gemüter erhitzte und einen der zweifellos entscheidenden Dispute des Jahrhunderts der Aufklärung auslöste. Ist er nicht doch, wie zuvor bereits angedeutet, auf vielerlei Weise in unserer Geschichte, ja vielleicht in unserem Denken präsent? Haben uns seine Texte heute nichts mehr zu sagen?

Die Fragestellungen, mit denen sich Cornelius de Pauw über weite Strecken seines Schaffens beschäftigte, sind gerade in ihrer kulturphilosophischen Stoßrichtung gewiss auch heute noch von größter Relevanz, will man die Geschichte

1 Vgl. Gerbi, Antonello: La Disputa del Nuovo Mondo. Storia di una Polemica: 1750-1900. Nuova edizione a cura di Sandro Gerbi. Mailand - Neapel: Riccardo Ricciardi Editore 1983.

2 Erwähnung findet das Werk de Pauws immerhin in Cañizares-Esguerra, Jorge: How to Write the History of the New World. Histories, Epistemologies, and Identities, in the Eighteenth-Century Atlantic World. Stanford: Stanford University Press 2001, S. 26-28.

Ә Open Access. (C) 2021 Ottmar Ette, publiziert von De Gruyter. (c) BY-NC-ND Dieses Werk ist lizenziert unter einer Creative Commons Namensnennung - Nicht-kommerziell - Keine Bearbeitung 4.0 International Lizenz. https://doi.org/10.1515/9783110703467-011 
der Beziehungen zwischen Europa und der außereuropäischen Welt mit historischer Tiefenschärfe begreifen. Dies gilt, um mit der Begrifflichkeit des 18. Jahrhunderts zu sprechen, ebenso für die „Indes occidentales“ wie für die „Indes orientales“, also für „Westindien“ wie für „Ostindien“ auf der Karte der kolonialen Expansion Europas. Denn der wegen seiner Scharfzüngigkeit gefürchtete Philosoph war ohne jeden Zweifel ein Denker der Globalität und sein gesamtes literarisch-philosophisches Werk eine Antwort auf jene zweite Phase beschleunigter Globalisierung, ${ }^{3}$ welche die zweite Hälfte des 18. Jahrhunderts bis deutlich über die Jahrhundertwende hinaus umfasst.

Dies war ein Zeitraum, der sich im Übrigen innerhalb des deutschsprachigen Raumes seit Mitte des Jahrhunderts auch in einer deutlich steigenden Zahl an Übersetzungen spanischer Geschichtswerke zur ersten Globalisierungsphase niederschlug. ${ }^{4}$ Das Interesse des Zeitalters der Aufklärung und damit der zweiten Phase beschleunigter Globalisierung an der ersten Phase sowie die damit verbundene koloniale Ausbreitung insbesondere der iberischen Mächte war in ganz Europa enorm.

Doch wie hatte man sich im 18. Jahrhundert unter nicht allein geographischen, sondern auch politischen und militärischen Vorzeichen die Gesamtheit unseres Planeten von Europa aus vorzustellen? Einheit und Aufteilung der gesamten Welt stellen zunächst unter geologischen und geomorphologischen Gesichtspunkten Problematiken dar, die de Pauws gesamtes Werk über die Alte wie die Neue Welt durchziehen. Dabei begreift der Autor der Recherches philosophiques sur les Américains ganz im Sinne der Naturgeschichte Buffons, die für ihn eine unhinterfragbare wissenschaftliche Leitlinie darstellt, diese ,Neue` Welt auch als eine geologisch wie geomorphologisch jüngere:

Die fast unendliche Anzahl von Seen \& von Sümpfen, von denen Westindien bedeckt ist, wurde nicht allein von den überschüssigen Flusswassern gebildet noch von den Nebeln, welche von den Bergen und den Wäldern angezogen werden: Diese Seen scheinen vielmehr aus Wasserdepots gebildet, die noch nicht aus den jeweiligen Orten auslaufen konnten, die einst von einer gewaltigen Erschütterung geflutet worden waren, welche der gesamten Maschine des Erdglobus ihren Stempel aufdrückte: Die zahlreichen Vulkane der Kordilleren \& die Felsen Mexikos, die Erdbeben, welche niemals in dem einen wie

$3 \mathrm{Vgl}$. hierzu erstmals Ette, Ottmar: Weltbewußtsein. Alexander von Humboldt und das unvollendete Projekt einer anderen Moderne. Weilerswist: Velbrück Wissenschaft 2002, S. 25-27; eine umfangreiche Übersicht der unterschiedlichen Phasen beschleunigter Globalisierung findet sich in Ette, Ottmar: TransArea. Eine literarische Globalisierungsgeschichte. Berlin - New York: Verlag Walter de Gruyter 2012.

4 Vgl. hierzu Birkenmaier, Anke: Versionen Montezumas. Lateinamerika in der historischen Imagination des 19. Jahrhunderts. Mit dem vollständigen Manuskript von Oswald Spenglers „Montezuma: ein Trauerspiel“ (1897). Berlin - New York: Verlag Walter de Gruyter 2011, S. 14. 
dem anderen Zweig der Anden aufhören, beweisen, dass in unserer Zeit die Erde dort noch nicht zur Ruhe gekommen ist. ${ }^{5}$

Die Vorstellungen des Cornelius de Pauw in erdgeschichtlicher oder geologischer Hinsicht entsprechen durchaus dem Stand der damaligen europäischen Wissenschaft über unseren Erdkörper. Der gesamte Planet bildet mithin eine Einheit, jene „Maschine des Globus“, die sich freilich naturhistorisch gesehen gleichzeitig in erdgeschichtlicher Ungleichzeitigkeit befindet. Dies entsprach vollkommen den empirisch nicht abgesicherten, aber systematischen Vorstellungen, die man sich von der Erdoberfläche in der Aufklärungsepoche machte, wobei Katastrophentheorien hierbei eine wichtige Rolle spielten. Denn während es in der Alten Welt längst zu einer gewissen Beruhigung (,repos“) gekommen sei, brodelt und schüttelt es in den Gebirgen der Neuen Welt, wo die Landmassen sich erst wesentlich später aus dem Wasser gehoben hätten und noch immer weite aquatische Binnenräume bildeten.

Dies bedeutet, dass sich die europäischen Philosophen des 18. Jahrhunderts die Erde als einen in Bewegung befindlichen Körper oder als „Maschine“ vorstellten, die keineswegs gleichzeitigen Erschütterungen ausgesetzt worden sei. Die Erdgeschichte der Alten Welt war mit der Erdgeschichte in der Neuen Welt nicht vergleichbar: Beide Welten, beide Hemisphären der Erde, waren streng voneinander geschieden. Die Unterschiede zwischen den Welten waren folglich unmittelbar sinnlich wahrnehmbar und von jedermann zu beobachten. Zur Erkundung der erdgeschichtlichen Verhältnisse bedurfte es keiner Forschungsreisen und keiner Expeditionen. Die ,Alte` und die ,Neue' Welt bildeten zwei voneinander verschiedene Hemisphären: ,Alt' steht dabei ,neu' direkt gegenüber beziehungsweise entgegen. Die Maschine des Erdkörpers ist zwar durchaus eine einzige, spaltet sich aber in zwei Hemisphären auf, die in ihrer Gegensätzlichkeit bis in unsere Tage fortbestehen und in ihrer Gewalt infolge der zahlreichen Erdstöße für den menschlichen Körper sinnlich erfahrbar werden. Die zahlreichen Vulkane der Kordillere der Anden waren dafür der beste Beweis. Aus eben diesem Grunde war es gegen Ende des Jahrhunderts Alexander von Humboldt so wichtig, auf seiner eigenen Forschungsreise durch die amerikanischen Tropen nicht nur die Tiefländer

5 Pauw, Cornelius de: Recherches philosophiques sur les Américains, ou Mémoires intéressants pour servir à l'Histoire de l'Espèce humaine. Berlin: Chez Georges Jacques Decker, Imp. du Roi 1768-

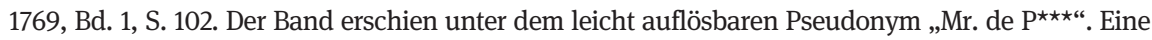
deutsche Ausgabe folgte im Übrigen rasch: Philosophische Untersuchungen über die Amerikaner, oder wichtige Beyträge zur Geschichte des menschlichen Geschlechts. Übersetzt von Carl Gottlieb Lessing. 2 Bde. Berlin: Decker und Winter 1769. Die französischsprachigen Originalausgaben verfügen über zahlreiche orthographische Nachlässigkeiten insbesondere bei der Akzentsetzung, die im vorliegenden Text nicht gesondert signalisiert werden. 
am Orinoco oder am Amazonas, sondern auch die Kordilleren zu erkunden und einzelne Vulkane zu besteigen. Seine Forschungen sollten die Vorstellungen einer systematischen, aber nicht empirisch fundierten Geographie und Geologie Stück für Stück zertrümmern und die geologisch-geographische Einheit beider Welten wiederherstellen. Doch zurück zur Vorstellungswelt des Cornelius de Pauw und seiner sich durchaus als wissenschaftlich fundiert verstehenden Welt-Anschauung!

Die naturhistorisch verankerte Unterscheidung und Scheidung zweier Hemisphären bildet die grundsätzliche diskursive Setzung seiner Recherches philosophiques sur les Américains. Von dieser Unterscheidung, von dieser Diskriminierung leitet sich alles andere ab. Sie ist zunächst zwar rationaler, aber nicht relationaler Natur. Sie gibt der Menschheitsgeschichte wohl einen Sinn, koppelt diesen aber wie wir sehen werden - von den Sinnen rasch wieder ab: Denn was die Natur (oder eben der christliche Gott) geschieden hat, ist auch bei den Menschen und ihrer Kultur strikt voneinander geschieden. De Pauws Recherches setzen auf die Macht des Sinns, nicht auf die Macht der Sinne und des sinnlich vom Reisenden wie vom Publikum Erlebbaren. Die sinnliche, empirische Überprüfung aller rein theoretischen Vorstellungen bleibt außerhalb seiner argumentativen Welt.

Dem im obigen Zitat deutlich werdenden Argumentationsschema folgen nicht allein die naturhistorischen, sondern auch die kulturhistorischen Überlegungen der Philosophischen Untersuchungen über jene Amerikaner, die selbstverständlich nicht - ich darf noch einmal daran erinnern - entgegen unserer aktuellen Sprachverwirrung die Bewohner der USA, sondern die indigene Bevölkerung des amerikanischen Kontinents bezeichnen. Sie allein - und nicht die erdgeschichtlichen Verhältnisse in der Neuen Welt - stehen im Fokus der Überlegungen des holländischen Philosophen.

Gleich zu Beginn seines „Discours Préliminaire“ zum ersten, 1768 unter dem Namen eines „Mr. de $\mathrm{P}^{\star \star \star \star}$ in Berlin erschienenen Bandes seiner umfangreichen Schrift machte de Pauw dabei deutlich, welches für ihn jenes historische Ereignis war, das aus seiner Sicht die Geschichte des Planeten am nachhaltigsten geprägt und gleichsam die naturhistorische Differenz zwischen Alter und Neuer Welt am stärksten hervorgetrieben hatte. Wir konnten diese menschheitsgeschichtliche diskursive Setzung schon bei einem Voltaire beobachten:

Es gibt kein denkwürdigeres Ereignis unter den Menschen als die Entdeckung von Amerika. Wenn man von den gegenwärtigen Zeiten in die entferntesten Zeiten hinaufsteigt, gibt es keinerlei Ereignis, das man mit diesem vergleichen könnte; \& ohne Zweifel ist es ein großes \& schreckliches Schauspiel, die eine Hälfte dieses Globus derart von der Natur benachteiligt zu sehen, insofern alles dort entweder degeneriert oder monströs war.

Welcher Naturforscher der Antike hätte jemals vermutet, dass ein und derselbe Planet zwei so unterschiedliche Hemisphären haben würde, von denen die eine von der anderen besiegt, unterworfen \& gleichsam verschlungen wurde, sobald ihr die andere bekannt, 
nach einem Ablauf von Jahrhunderten, die sich in der Nacht \& in den Abgründen der Zeit verlieren?

Diese erstaunliche Revolution, welche das Antlitz der Erde \& das Schicksal der Nationen veränderte, war absolut augenblicklich, weil es auf Grund einer fast unglaublichen Fatalität keinerlei Gleichgewicht zwischen Angriff und Verteidigung gab. Alle Gewalt \& alle Ungerechtigkeit waren auf Seiten der Europäer: Die Amerikaner hatten nur ihre Schwäche, so mussten sie ausgelöscht werden, \& wurden ausgelöscht in einem Augenblick. ${ }^{6}$

Der nicht umsonst an Jesuitenkollegs in Lüttich und Köln ausgebildete und überdies wohl an der für außereuropäische Fragen bestens ausgestatteten Göttinger Universität eingeschriebene Cornelius oder Corneille de $\mathrm{Pauw}^{7}$ entfaltete in den wie stets bei ihm scharf konturierten Wendungen seines französischsprachigen Werkes eine Gegensätzlichkeit, welche die Opposition von ,alter` und ,neuer` Welt nun auf jene von ,Europäern' und ,Amerikanern' übertrug. Sie sind Bewohner einer Welt, die schroffer zweigeteilt jedoch kaum vorgestellt werden könnte. Cornelius de Pauw gelang es diskursiv wie rhetorisch blendend, im weiteren Verlauf seiner Argumentation diese Zweiteilung vor allem auf der kulturgeschichtlichen und zivilisationsgeschichtlichen Ebene fruchtbar zu machen und die eingeborenen Völker Amerikas als den Europäern hoffnungslos unterlegen und schwach darzustellen. Was brauchte es da noch Überprüfungen vor Ort und empirisch fundierte Kenntnisse über die altamerikanischen Kulturen in Mexiko oder Peru?

Die in dieser Eingangspassage diskursiv in Gang gesetzten Mechanismen der Inklusion und Exklusion erzeugen somit eine strukturelle Ambivalenz, die im Ergebnis der hier evozierten geschichtlichen Prozesse jedoch sofort in eine radikale Scheidung zurückgenommen wird. Cornelius de Pauws Recherches philosophiques sur les Américains wirkten auf die europäischen Zeitgenossen überzeugend, weil eine scheinbar natürliche Zweiteilung auch auf der kulturellen Ebene vollständig durchgehalten wurde und damit die kulturelle Inferiorität der indigenen Bevölkerungen gleichsam naturhistorisch verankert schien.

Diese natur- wie kulturhistorische Zweiteilung bestimmt geschichtsphilosophisch die gesamte Anlage des de Pauw'schen Schreibens, das im Zeichen eines großen Zusammenstoßes steht, welcher im Grunde noch immer kein Ende gefunden habe. Denn die Auseinandersetzungen zwischen beiden Welten gehen auch im 18. Jahrhundert, im Zeitalter der Aufklärung mit nochmals verstärkten Kräften

6 Ebda., Bd. 1, S. a2v f.

7 Vgl. hierzu Church, Henry Ward: Corneille de Pauw, and the controversy over his „Recherches philosophiques sur les Américains,.. In: PMLA (New York) LI, 1 (March 1936), S. 180 f.; sowie Beyerhaus, Gisbert: Abbé de Pauw und Friedrich der Große, eine Abrechnung mit Voltaire. In: Historische Zeitschrift (München - Berlin) 134 (1926), S. 465-493. 
weiter. Die europäischen Mächte treffen auf die amerikanischen - und dies wahrlich nicht in einer Art und Weise, wie man sie später als ,Begegnung der Kulturen“ zu bemänteln gesucht hat. Aus der Perspektive von de Pauw war der Ausgang dieses Zusammenstoßes geradezu von der Natur her vorbestimmt und damit der (bösen) Absicht der Europäer entzogen. Dies aber verleiht der ungeheuren Macht in ihrer Asymmetrie ihren geschichtsphilosophisch begründeten Sinn. Man versteht, warum eine solche Argumentation noch einen Hegel beeindrucken musste.

Kultur wird in dieser Argumentation folglich in Natur transformiert: Die geschichtlichen Vorgänge erscheinen als ,natürlich‘. Und mehr noch: Die Welt Amerikas wird in ein Reich der Natur (zurück-)verwandelt, während Europa im Zeichen einer erfolgreich vorrückenden Kultur erscheint. Dieses Vorrücken Europas wiederum zeigt sich als quasi-natürlich, als gleichsam naturgegeben. Aus dem Bereich der Kultur aber wird die Neue Welt folgenreich exkludiert.

So entfaltet sich eine Mechanik, die mit unbeirrbarer Kraft immer weiter voranschreitet. Was naturhistorisch gegensätzlich angelegt ist, äußert sich mit geradezu deterministischer Gewalt auf kulturhistorischer Ebene. So steht die kulturell erzeugte Macht der Europäer der ,natürlichen‘ Ohnmacht und Schwäche der Amerikaner statisch und gleichsam absolut gegenüber. Die Schwäche der indigenen Bevölkerung aber ist diejenige der amerikanischen Natur, die noch in stetiger Unruhe ist und keine Zeit finden konnte, sich langsam zu stabilisieren und zu kräftigen. Wir haben es hier mit jener (gezielten) Konfusion von Biologie und Kultur zu tun, die Claude Lévi-Strauss in seiner Auseinandersetzung mit ,Rasse“ und Geschichte so stark betont hatte:

\begin{abstract}
Aber die Erbsünde der Anthropologie besteht in der Verwechslung zwischen einem rein biologischen Begriff von Rasse (wenn man denn überhaupt annimmt, dass dieser Begriff aus einem Grenzgebiet überhaupt auf irgendeine Objektivität Anspruch erheben könnte, was die moderne Genetik bestreitet) und den soziologischen und psychologischen Produktionen der menschlichen Kulturen. ${ }^{8}$
\end{abstract}

Die prägnanten Formulierungen des französischen Anthropologen, kurze Zeit nach dem Ende des Rassenwahns und der rassemedizinischen Gräueltaten der Nazis in Deutschland formuliert, mögen uns eine Leitlinie dafür bieten, die Positionen de Pauws im Kontext eines Rassedenkens wie eines langsam entstehenden wissenschaftlichen Rassismus neu zu verorten und neu $\mathrm{zu}$ denken. Alles Leben der Natur wie der Kultur wird in dem obigen Textauszug de Pauws miteinander in Beziehung gesetzt und ins Zeichen der Scheidung zwischen Alter und Neuer Welt, dieser Konstruktion der gesamten Erde in Form einer schroffen Opposition gestellt.

8 Lévi-Strauss, Claude: Race et histoire. Suivi de L'œuvre de Claude Lévi-Strauss par Jean Pouillon. Paris: Denoël 1984, S. 10. 
Dabei wird freilich nicht vergessen, dass die beiden so unterschiedlichen Hemisphären noch immer die Einheit eines von einer tiefen Trennung durchlaufenen Planeten bilden. Die angebliche physische und kognitive Schwäche der indigenen Bevölkerungen aber wird als quasi-natürlich angenommen und stellt einen Teilaspekt des Gegensatzes zwischen Stärke und Schwäche dar, welcher naturhistorisch verankert wird, wodurch Natur und Kultur nicht länger als voneinander trennbar erscheinen.

So fügte Cornelius de Pauw bereits dem Incipit seines sicherlich meistdiskutierten und umstrittensten Werkes jene grundlegenden Isotopien bei, welche seine Recherches philosophiques sur les Américains in ihrer Gesamtheit durchziehen. Es handelt sich um eine bewusste literarisch-rhetorische Arbeit, die gerade durch ihre oft polemische Pointe - der de Pauw seine rasche Bekanntheit wie wohl auch sein nicht weniger rasches Vergessen verdankte - ihre Wirkung auf die zeitgenössische internationale Leserschaft nicht verfehlte. Ein größerer Gegensatz als jener zwischen ,Alter' und ,Neuer‘ Welt wird als kaum denkbar präsentiert - und dies ebenso auf Ebene der Natur wie auf jener der Kultur. Der Text entfaltet die Macht eines einzigen Sinnes, einer einzigen Bewegungsrichtung, deren Vektorizität klar festgelegt und für den Philosophen offenkundig ist. Kultur und Zivilisation erscheinen als natürlicher Ausfluss der Natur.

Die Langzeitwirkung der de Pauw'schen Analyse darf - auch wenn der Name ihres Verfassers aus vielen Werken und Kompendien des 19. Jahrhunderts verschwunden ist - ebenso wenig unterschätzt werden wie die Vielfalt an philosophischen und politischen Folgen, die sie zeitigte. Ich hatte bereits auf den direkten Einfluss von de Pauw auf einen der großen philosophischen Denker des 19. Jahrhunderts in Deutschland aufmerksam gemacht. Denn noch Hegels weltgeschichtlicher Entwurf zeigt gerade mit seiner sattsam bekannten These von der Inferiorität Amerikas, seiner naturräumlichen Ausstattung, seiner Tiere und seiner indigenen Bevölkerung die unverkennbaren Spuren eines Denkens, das Cornelius de Pauw mit seinen Recherches philosophiques sicherlich auf die argumentative Spitze getrieben hatte. In Hegels Vorlesungen über die Philosophie der Weltgeschichte sind diese Vorstellungen noch immer höchst lebendig, verweist der Philosoph doch in Übernahme eines solchen Denkens mit Blick auf die Neue Welt darauf, dass diese Weltteile „nicht nur relativ neu, sondern überhaupt neu, in Ansehung ihrer ganzen physischen und geistigen Beschaffenheit,“9 seien. Auch an dieser Stelle können

9 Hegel, Georg Wilhelm Friedrich: Vorlesungen über die Philosophie der Weltgeschichte. Bd. XII. Auf Grund des aufbehaltenen handschriftlichen Materials neu herausgegeben von Georg Lasson. Leipzig: Felix Meiner ${ }^{2}$ 1923, S. 107. 
wir unschwer die von Lévi-Strauss inkriminierte „Confusion“ von Natur und Geist, die gezielte Vermischung von natürlichen und kulturellen Dingen erkennen. Die Kulturen in Mexiko oder Peru, also bei den Azteken oder bei den Inkas, seien „ganz natürliche“10 gewesen. Hegel zweifelte daher nicht an der „Inferiorität dieser Individuen in jeder Rücksicht, selbst in Hinsicht der Größe“11, so dass es aus Sicht seiner geschichtsphilosophischen Thesen nur ,natürlich“ war, dass diese Kulturen - wenn er denn überhaupt von „Kulturen“ sprechen wollte - von der Erdoberfläche verschwinden. Sie hatten keinen Platz in seiner Geschichtsteleologie.

Auch in solchen Zusammenhängen wird die Kultur der Anderen, der NichtEuropäer, der Bewohner der Neuen Welt dadurch negiert, dass sie in Natur rückverwandelt und damit historisch ausgeschaltet wird. Es genügt, dass sich ihr der (europäische) Geist nähert, um all dies in seiner Irrelevanz für die Menschheitsgeschichte sichtbar werden zu lassen und zum Einsturz zu bringen: Die amerikanischen Kulturen, die verschiedenartigen Kulturen der indigenen Völker haben für Hegel keinen Wert an sich. Eine eigene Studie könnte zweifellos erhärten, auf welch grundlegende Weise die gewiss nicht von de Pauw erfundene, aber von seinen erfolgreichen Schriften sehr weit auf die Reflexion des Verhältnisses zwischen europäischer und außereuropäischer Welt ausstrahlende Methode gerade im 19., ja bis weit ins 20. Jahrhundert hinein wirkte. Wie aber ließe sich diese Methode näher beschreiben?

Mit Blick auf seine Denk- und Vorgehensweise gilt es zunächst einmal festzuhalten, dass der andere Teil der Welt weder im Incipit noch im weiteren Verlauf der Recherches philosophique, die nicht umsonst sur les Américains betitelt sind, selbst zu Wort kommt. Wie sollte er dies auch? Denn ihm fehlen, folgt man de Pauw, die Worte, um sich differenziert auszudrücken. So heißt es in seinem einflussreichen Beitrag zum Supplément der Encyclopédie hinsichtlich der von ihm mit Blick auf die Bewohner Amerikas behaupteten Sprachlosigkeit:

[...] die Armut ihrer Sprache, deren Wörterbuch auf einer einzigen Seite Platz fände, hindert sie daran, sich zu erklären. Man weiß, dass selbst die Peruaner, auch wenn sie in einer Art politischer Gesellschaft vereint waren, noch keine Begriffe erfunden hatten, um die metaphysischen Seinsweisen oder die moralischen Qualitäten auszudrücken, welche den Menschen am stärksten vom Vieh unterscheiden, Begriffe also wie Gerechtigkeit, Dankbarkeit, Barmherzigkeit. Diese Qualitäten zählten zu jenen Dingen, welche keinen Namen besaßen: Die Tugend selbst hatte keinerlei Namen in diesem Lande, über welches man so viele Übertreibungen zum Besten gab. Nun, bei den kleinen umherziehenden Völkern ist die Hungersnot an Wörtern noch unvergleichlich größer; und dies in einem

10 Ebda.

11 Ebda., S. $107 \mathrm{f}$. 
Maße, dass jede Art von Erläuterung über Gegenstände der Moral \& Metaphysik bei ihnen unmöglich ist. ${ }^{12}$

Ein Wörterbuch von einer einzigen Seite? Cornelius de Pauws Äußerungen gehen an derartigen Stellen weit hinter den eigentlichen Wissensstand der Europäer über die Sprachen in der Neuen Welt zurück. Denn selbstverständlich wusste man, dass die Inkas, die im obigen Zitat direkt angesprochen werden, über eine komplexe Sprache verfügen, von der nicht nur Grammatiken, sondern ausführliche Wörterbücher erstellt wurden, die selbstverständlich weit über eine Seite hinausgehen. Doch de Pauw unterschlug dieses Wissen geflissentlich und setzte an dessen Stelle eine Vielzahl unhaltbarer Behauptungen, die sich freilich in vielen europäischen Köpfen einnisteten. Er machte die Sprache zum Verhandlungsort einer Bewertung von Kulturen und eröffnete damit - gemeinsam mit anderen europäischen Denkern - ein Spielfeld, welches im 19. Jahrhundert breit von der Philologie in Anspruch genommen und zum Entstehungsort unterschiedlicher Rassismen gemacht wurde. $^{13}$

Sprache wird fortan zum Bestimmungsort menschlicher Kultur und menschlicher Kognition, ja einer gegebenen oder nicht gegebenen Möglichkeit künftiger Perfektibilität. Sprache - und die Verfügung über Sprache - wird in diesen wohlkalkulierten Wendungen in einen fundamentalen Bezug zu einer nicht zuletzt politischen Entmündigung gebracht, wobei der Bezug zwischen Sprachfähigkeit und Physis im Kontext der gesamten Passage ähnlich strukturiert wird wie in der eingangs untersuchten Relation zwischen naturhistorischer und kulturhistorischer Inferiorität. Diese Relation disqualifizierte - wie wir bereits sahen - alles Amerikanische als monströs oder degeneriert.

Dies musste weitreichende Konsequenzen haben: Denn wie hätten sich die indigenen Kulturen gegenüber derlei Vorwürfen verteidigen können, wenn sie doch nicht einmal über ihre eigene Sprache verfügten? Der holländische Philosoph tritt damit geradezu notwendig an die Stelle derer, die über keine Wörter, keine abstrakten Begriffe und damit auch über keine Macht (und Fähigkeit in jeglichem Sinne) verfügen. Er wird zum Wortgewaltigen, des Wortes Mächtigen schlechthin und spricht folglich anstelle derer, denen angeblich keine ausreichend differenzierte

12 Pauw, Cornelius de: Amérique. In: Supplément à L'Encyclopédie ou Dictionnaire raisonné des Sciences, des Arts et des Métiers. Par une Société de Gens de Lettres. Mis en ordre et publié par $M^{* * *}$. Tome premier. Amsterdam: Chez M.M. Rey, libraire 1776, S. 352.

13 Vgl. hierzu die Ergebnisse eines von Markus Messling geleiteten Potsdamer Forschungsprojekts mit der Habilitationsschrift von Messling, Markus: Gebeugter Geist. Rassismus und Erkenntnis in der modernen europäischen Philologie. Göttingen: Wallstein Verlag 2016; sowie der Dissertation von Lenz, Markus Alexander: Genie und Blut. Rassedenken in der italienischen Philologie des neunzehnten Jahrhunderts. Paderborn: Wilhelm Fink Verlag 2014. 
Sprache zur Verfügung steht. Der Europäer spricht damit nicht allein über die Amerikaner, er spricht auch für sie und an ihrer Stelle. Dies ist eine Selbstermächtigung, deren fundamentale Folgen wir überdenken müssen.

Was kümmerte da den großen europäischen Philosophen der Wissensstand der Epoche? So zahlreich zu jenem Zeitpunkt die meist von Missionaren zusammengestellten Grammatiken und Wörterbücher unterschiedlichster amerikanischer Sprachen waren: Cornelius de Pauw beharrt auf jener amerikanischen „disette des mots“, welche ihm die Macht verleiht, seine eigenen an die Stelle der Wörter des Anderen (und zum Anderen Gemachten) zu setzen. Dieser zutiefst sinnbildende und sinngebende Vorgang ist in seiner Bedeutung kaum zu überschätzen: Der vorgebliche Sprachenspezialist und Philologe spricht auch im weiteren Verlauf nur über, niemals aber mit (Worten) der indigenen Bevölkerung, die - nebenbei bemerkt - natürlich nicht nur über eine, sondern über eine außerordentlich hohe Zahl unterschiedlichster Sprachen auf dem amerikanischen Kontinent verfügt.

Dabei zeigt sich bereits im Incipit der de Pauw'schen Recherches philosophiques sur les Américains, dass sich Europa, dass sich das Europäische nur zu begreifen vermag, wenn es sich in einen weltweiten Vergleich stellt (freilich: nach eigenen Regeln und ganz im Sinne der eigenen Macht). Europa, so scheint es, kann nur Europa sein, wenn es sich gegenüber außereuropäischen Kulturen als überlegen absetzt. Der Ausgang dieses Vergleichs ist vorbestimmt, eine Reziprozität zwischen beiden Seiten des Atlantik nicht gegeben.

Das Lexem „européen“ erfüllt fortan in den Recherches philosophiques die diskursive Aufgabe, ein Eigenes - durchaus in seiner internen europäischen Vielgestaltigkeit - von einem außereuropäischen Anderen abzusetzen, ohne dass beide quasi berührungslos nebeneinander koexistierten. Denn sie verbindet, was sie auf tragische Weise trennt: die Geschichte einer Asymmetrie der Macht, die keineswegs allein die evidente Ungleichheit ihrer materiellen Waffenarsenale betrifft. Europa aber kann nach der ersten Phase beschleunigter Globalisierung, deren früher historischer Höhepunkt die sogenannte ,Entdeckung‘ Amerikas durch Kolumbus war, nicht länger ohne Außereuropa konzipiert werden. Dies wird auch von Cornelius de Pauw unterstrichen, erachtete er sie doch, wie wir sahen, als das größte und einschneidendste Ereignis in der bisherigen Geschichte der gesamten Menschheit. Der Augenblick der Entdeckung und Beherrschung Amerikas ist der Ausgangspunkt, von dem aus der in Amsterdam geborene Abbé seine Leserinnen und Leser in seine Neue Welt führt. Dies ist zugleich der Sinn, den de Pauw seinen Untersuchungen mit aller Macht zu vermitteln sucht - ein Sinn, der sich der Wahrnehmung der Sinne weitgehend entzieht und sich allein dem Universum der Texte anvertraut. Denn in der Tat bewegen wir uns, wie schon Francisco Javier Clavijero kritisch anmerkte, in einem Netzwerk von europäischen Texten über die Neue Welt, in welchem nur die Europäer, nicht aber die Amerikaner zu Wort kommen. 
Die Recherches philosophiques sur les Américains bilden ein Werk aus Worten, das sich auf keinen empirischen, von de Pauw sinnlich erfahrenen Gegenstand, sondern ausschließlich auf andere Werke und Worte, auf andere Texte bezieht. Um über die Neue Welt und ihre Kulturen schreiben zu können, muss man nicht reisen, muss man keine Expeditionen dorthin unternehmen, muss man sie nicht kennenlernen, muss ihre Sprachen nicht sprechen, geschweige denn mit ihren Bewohnern überhaupt reden. Denn was könnten der Sprache nicht mächtige Einheimische einem schon über ihre eigene Welt sagen? So stehen diese Schriften des Holländers für das ein, was man als eine Textwissenschaft im schwachen Sinne bezeichnen könnte. Weder hat der holländische Abbé je die Neue Welt gesehen und bereist noch hat er - wie etwa nach ihm Guillaume-Thomas Raynal - ein weitgespanntes Netz von Korrespondenten auch in Übersee unterhalten und transatlantisch Informationen ausgetauscht. Die Methode des Cornelius de Pauw, so ließe sich (auch mit Francisco Javier Clavijero) sagen, war rein textbasiert: In diesem Sinne ist sie philologisch, zielt auf den Sinn und schließt die Sinne textuell weitgehend aus. Dabei handelt es sich um eine europäische und weit mehr noch eurozentrische Philologie, insofern alle Texte, auf die sich diese Textwissenschaft stützt, europäische Texte und Texte von Europäern sind.

Mit guten Gründen könnte man daher die Recherches philosophiques sur les Américains als eine nicht enden wollende Reise durch die Welt der europäischen Texte, nicht aber durch die Welt sinnlichen Erlebens und die Resultate empirischer Forschungen charakterisieren. Ohne jegliche empirische Basis, ohne jede Reise zu seinen Gegenständen und ohne direkte Kenntnis der von ihm beschriebenen, diskutierten und bewerteten Objekte (in) der Neuen Welt konsultierte de Pauw ebenso historische Chroniken wie zeitgenössische Reiseberichte, ebenso ihm zugängliche Bordbücher wie Manuskripte von Handelsreisenden, ebenso historiographische Werke des 16. Jahrhunderts wie philosophische Traktate des 18. Jahrhunderts. In seinem Xanten häufte de Pauw eine große amerikanistische Bibliothek auf, welche seine Thesen zu stützen bereit stand.

In den Bewegungen zwischen den Texten entsteht nicht nur eine gewisse Autonomie der von ihm durchquerten Textuniversen, sondern vielleicht mehr noch eine textuell erzeugte Autonomie und Eigen-Logik eines „Philosophe“, der von einer erhöhten philosophischen Beobachterposition aus seine Urteile fällt und im Namen einer universalen Vernunft zu sprechen vorgibt. Letztere ist allein textbasiert, ist philologisch - und monologisch europäisch. Die dadurch erzeugte Kohärenz machte zweifellos die Faszinationskraft und auch die damit verbundene Wirkmächtigkeit seines stets an klarer Sinngebung interessierten Schaffens aus. Sie beruht weniger auf Beherrschung der Gegenstände als auf Beherrschung der Texte: Denn allein auf letztere kommt es an. Die Philologie de Pauws könnte man sehr wohl als Macht, ja als Gewalt über Texte begreifen. 
Daher gründet sich de Pauws eigenes Verständnis der amerikanischen Geschichte - wie er in seinem bereits erwähnten Artikel für den Supplement-Band der Encyclopédie festhielt - auf einem kritischen (wenn auch nur im Kritiker selbst verankerten) Umgang mit den historischen Quellentexten und damit auf einer spezifischen Qualität der eigenen Lektüre. An deren Qualität knüpfen sich bestimmte Anforderungen:

\footnotetext{
Wenn man eine Vorstellung vom Zustand erhalten will, in welchem sich die Neue Welt zum Zeitpunkt ihrer Entdeckung befand, muss man die Berichte studieren \& ohne Unterlass eine kluge \& strenge Kritik anwenden, um die Verfälschungen \& die Wunder abzutrennen, von denen sie nur so wimmeln: Die Zusammenstellungen, zumeist ohne jeden Geist verfasst, häufen alles auf, was sie in den Journalen von Reisenden finden \& lassen daraus abgeschmackte Romane entstehen, welche sich in unseren Tagen nur allzu sehr vervielfacht haben; weil es leichter ist, ohne jedes Nachdenken zu schreiben, als nachdenkend zu schreiben. ${ }^{14}$
}

Der für den Aufklärungsphilosophen Cornelius de Pauw wichtigste Begriff ist hier zweifellos die Kritik, von der wir bereits zu Beginn unserer Vorlesung sahen, dass sie fraglos einer der höchsten Werte der Aufklärung ist. Denn die Kritik verschafft gegenüber den vorhandenen Gegenständen und Texten jene notwendige Distanz, von der aus mit Augenmaß beurteilt (oder gegebenenfalls verurteilt) werden kann. Woran aber soll sich diese Kritik orientieren? Was sind wiederum ihre Kriterien, welches ihre Grundlagen? Bei Cornelius de Pauw gelangen wir an die Grenzen aufklärerischer Kritik: Denn weder legt der „Philosophe“ seine Kriterien offen noch besitzt er mit Blick auf die Neue Welt Kenntnisse, die ihm dabei helfen würden, das Vorgefundene vom Erfundenen zu scheiden. Allein von Europa aus soll alles kritisch bewertet und gelesen werden.

Für de Pauw jedoch, so scheint es, existiert Kritik als Wert an sich, der im kritischen Subjekt verankert ist. Erst die kritische Lektüre des zuvor Geschriebenen ermöglicht ein Schreiben, das diese Lektüre reflektiert: Lesen und Schreiben sind die grundlegenden Handlungen, die im Mittelpunkt des de Pauw'schen Textuniversums stehen. Das „écrire en réfléchissant“ spiegelt diese Bewegung des Reflektierens des Gelesenen und dessen Transformation in den Schreibakt wider. Die Normen und Kriterien für die Beurteilung dessen, was in dieser Welt der Texte als glaubwürdig gilt oder als lügnerisch ausgeschlossen werden muss, können allein von einem aufgeklärten Europa, ja von Xanten oder von Preußen aus definiert werden. Die Amerikaner sind Objekte, nicht aber Subjekte eines nicht auf Reziprozität beruhenden Diskurses, der ihnen mit Macht das Wort abschneidet und ihrer Existenz im Weltganzen einen klar umrissenen Sinn als Gegenstände und als Gehandelte in der Geschichte beimisst. Aus Sicht dieser neuweltlichen ,Gegenstände،

14 Pauw, Cornelius de: Amérique, S. 353. 
handelt es sich folglich um eine Kritik ohne Kriterien, die den Phänomenen der Neuen Welt angemessen wären.

Welches Bild des (indigenen) Amerikaners also entfaltet de Pauw auf der Grundlage der nach seinem Verständnis textkritischen Arbeit? Es ist in jedem Falle ein stereotypes Bild, das seinerseits nichts zu tun hat mit jenem Heterostereotyp des „bon sauvage“:

Er ist im eigentlichen Sinne weder tugendhaft noch böse: Welches Motiv hätte er, es zu sein? Die Schüchternheit seiner Seele, die Schwäche seines Geistes, die Notwendigkeit, sich sein Überleben inmitten der Hungersnot verschaffen zu müssen, die Herrschaft seines Aberglaubens \& die Einflüsse des Klimas führen ihn fort \& führen ihn sehr weit fort; doch er bemerkt es nicht einmal. Sein Glück ist es, nicht zu denken, in einer vollkommenen Untätigkeit zu verharren, viel zu schlafen, sich um nichts zu sorgen, sobald sein Hunger befriedigt ist, \& und sich lediglich um die Mittel zu sorgen, Nahrung zu finden, sobald der Hunger ihn wieder umtreibt. Er würde keine Hütte bauen, wenn die Kälte \& die Unwirtlichkeit der Luft ihn nicht dazu zwängen: Er würde seine Hütte nicht verlassen, würde er daraus nicht von seinem Bedürfnis verjagt: Seine Vernunft reift nicht: Bis zu seinem Tode bleibt er ein Kind, sieht nichts voraus, vervollkommnet nichts \& lässt die Natur unter seinen Augen, unter seinen Händen, degenerieren, ohne sie jemals zu stärken \& ohne sie aus ihrer Erschöpfung zu ziehen. Von Natur aus zutiefst faul, ist er rachsüchtig aus Schwäche \& grauenhaft in seiner Rache, weil er selbst unempfindlich ist: Da er nichts zu verlieren hat als das Leben, sieht er alle seine Feinde als seine Mörder an. ${ }^{15}$

Dies ist ein Bild des Amerikaners, des Indianers, des Eingeborenen, wie es eindimensionaler und negativer kaum sein könnte. Denn es gibt nichts, was den Indigenen antreibt, nichts, was ihn zu Anstrengungen führt, nichts, was ihn seine Lage verbessern lässt, da es bei ihm einzig und allein um die Befriedigung seiner simpelsten Bedürfnisse wie Hunger und Schlaf gehen kann. Er empfindet in keiner Weise das Bedürfnis, die Natur, seine Situation oder gar sich selbst zu vervollkommnen, da er nicht daran interessiert ist, aus seiner Lethargie zu erwachen, ja überhaupt einmal zu denken. Zukunft und Vergangenheit interessieren ihn nicht: Er sorgt sich nicht um das Vergangene, lebt bestenfalls in einer Gegenwart, die ihm nicht zu denken gibt, und sieht für die Zukunft nichts voraus, ja trifft keinerlei Vorkehrungen für das, was kommen könnte. Das Denken ist für den Indianer de Pauws eine Tätigkeit, die ihm in keiner Weise eigen ist.

Die in dieser Passage erwähnte „insensibilité“ des Indigenen steht - wie gleich zu zeigen sein wird - in direkter Verbindung mit einer Stumpfheit der Sinne, wie sie de Pauw für den weit überwiegenden Teil der nicht-europäischen Menschheit nicht nur annimmt, sondern ,fest-stellt‘. De Pauw spricht dem Rest der Menschheit ab, was er den Europäern im Übermaß zuerkennt: die Fähigkeit

15 Pauw, Cornelius de: Recherches philosophiques sur les Américains, Bd. 1, S. 123. 
zu denken und das eigene Schicksal zu verbessern. Der Reduktion der unterschiedlichsten amerikanischen Kulturen auf das statische Bild ,des' Amerikaners entspricht die Reduzierung dieses Menschen auf eine quasi tierische Existenz, die von keinerlei Entwicklung, keinerlei Dynamik und keinerlei Perfektibilität gekennzeichnet ist. Kultur wird in Natur umcodiert: Die Stumpfheit und Borniertheit des Indigenen erscheinen gleichsam als natürlich - und daher natürlich auch als verzichtbar. Denn er verfügt nicht über eine wie auch immer geartete Kultur.

Damit wird ,der‘ ursprüngliche Bewohner Amerikas - in einer unüberwindlichen Unmündigkeit gefangen - de facto aus der Geschichte der Menschheit ausgeschlossen, zu der er nichts beizutragen scheint; ja mehr noch: Er wird aus dem Menschengeschlecht ausgebürgert. Es handelt sich um eine Exklusion, die im zweiten, 1769 ebenfalls in Berlin erschienenen Band noch radikaler ausgestaltet wird. Für diese zusätzliche Radikalisierung de Pauws gab es keine in der Forschung liegenden Gründe, sondern eher solche, die auf das Publikum in der République des Lettres schielten und einen noch höheren Erfolg bei noch weiter zugespitzten Thesen versprachen. So lesen wir im zweiten Band von der Spezies Mensch - und nicht umsonst geht es in den Recherches philosophiques de Pauws laut Untertitel um nichts weniger als um die Histoire de l'Espèce humaine - im Allgemeinen:

Das wahrhafte Land, wo seine Spezies immer florierte \& prosperierte, ist die gemäßigte Zone im Norden unserer Hemisphäre: Dies ist der Sitz seiner Macht, seiner Größe \& seines Ruhmes. Rückt man weiter nach Norden vor, so werden seine Sinne stumpf \& zerfasern sich: so festigen sich seine Fibren und seine Nerven \& stärken sich durch die Wirkung der Kälte, die sie zusammenziehen, \& so verlieren seine Organe an Freiheit; desto mehr scheint die Flamme des Genies in allzu robusten Körpern zu erlöschen, wo alle Lebensgeister damit beschäftigt sind, die Federn der gesamten Struktur \& der tierischen Ökonomie in Gang zu halten. [...] Unter dem Äquator verändert sich seine Hautfarbe \& wird dunkel; die Züge einer entstellten Physiognomie revoltieren durch Rauheit: Das Feuer des Klimas verkürzt das Ende seiner Tage \& verstärkt die Glut seiner Leidenschaften, worauf die Sphäre seiner Seele sich zurückzieht: Er hört auf, sich selbst regieren zu können und kommt aus der Kindheit nicht mehr heraus. Mit einem Wort, er wird zu einem Neger, \& dieser Neger wird zum Sklaven der Sklaven.

Wenn man folglich die Bewohner Europas ausnimmt, wenn man vier oder fünf Völker Asiens ausnimmt \& einige kleinere Kantone Afrikas, dann setzt sich die überwiegende Mehrzahl des Menschengeschlechts aus Individuen zusammen, die weniger Menschen als wilden Tieren ähneln: Und doch nehmen diese sieben- bis achtmal mehr Raum auf unserem Globus ein als alle zivilisierten Nationen zusammen, \& sie verlassen ihr Vaterland so gut wie nie. Hätte man nach Amerika nicht Afrikaner gegen ihren Willen transportiert, so wären sie niemals dorthin gegangen: die Hottentotten reisen nicht mehr als die Orang Utans. ${ }^{16}$

16 Pauw, Cornelius de: Recherches philosophiques sur les Américains, Bd. 2, S. 68 f. 
Es entbehrt in dieser Passage nicht einer unfreiwilligen Komik, dass gerade Cornelius de Pauw, der selbst nicht in die von ihm behandelten Gebiete reiste, dem Reisen eine so hohe, ja entscheidende Bedeutung für die Ausprägung kultureller und zivilisatorischer Fähigkeiten und Vervollkommnungen beimisst. Der Zusammenhang zwischen Klima und Entfaltung des Menschengeschlechts, den de Pauw in dieser Passage konstruiert, steigert sich in seinem Verlauf immer mehr in ein Rassedenken, das sich pseudo-wissenschaftlich verproviantiert und damit vom europäischen Rassismus kaum noch eine Handbreit entfernt ist. Die einst von Montesquieu entfaltete und an Europa ausgerichtete Klimatheorie wird Jahrzehnte später bei de Pauw zum Instrument überspitzten Rassedenkens, das für die europäischen Nationen einen weitaus größeren Anteil an der Besiedlung des Erdkörpers einfordert und den überwiegenden Teil der Menschheit dem Tierreich zurechnet.

Im Laufe dieser um wissenschaftliche Begründungen auf dem Stand des 18. Jahrhunderts ringenden Argumentation wird deutlich: Die Mehrheit der Menschen wird in das Menschengeschlecht nur inkludiert, um sie danach umso besser exkludieren und die Europäer an die Spitze eines so definierten Menschseins setzen zu können. Allein in der gemäßigten Zone Europas habe sich die Menschengattung so prächtig entwickelt, dass sie in der Tat für ein vollständiges, vollkommenes Menschsein eintreten könne.

Die Europäer sind hier die einzigen Bewohner der Erdkugel, die zwischen großer Hitze und großer Kälte leben und daher von der Natur (oder vom christlichen Gott) in ihrer Entwicklung begünstigt sind. Aus der klimatheoretisch erzeugten Inferiorität und ,ewigen Kindheit‘ aber kann mit Cornelius de Pauw sehr wohl das Recht abgeleitet werden, die von der Natur weniger Begünstigten einer wohlverdienten Sklaverei zuzuführen, die notwendig unter der weisen Führung der europäischen Menschheit stehen muss. In dieser wie in nachfolgenden Passagen rechtfertigt Cornelius de Pauw folglich eine Expansion der Europäer auf Kosten jener Stämme und Horden, die sieben- bis achtfach mehr Raum auf dem Globus einnähmen als alle zivilisierten Völker („nations policées“) zusammen. Dass mit Hilfe derartiger Argumentationen Cornelius de Pauw einem verstärkten europäischen Kolonialismus das Wort reden will, kann wohl kaum bezweifelt werden.

Die machtpolitischen Konsequenzen liegen folglich auf der Hand. Die somit letztlich zweigeteilte Menschheit ist aber ebenso unauflöslich aneinander gekettet wie die zweigeteilte Welt auf Gedeih und Verderb aufeinander bezogen und miteinander verwoben ist. De Pauw entfaltet so das Denken einer Globalität, die unaufhebbar von einer fundamentalen Gegensätzlichkeit geprägt ist und diese Opposition - auf der wissenschaftlichen Grundlage der Buffon'schen Histoire naturelle und Montesquieus Klimatheorie - in Begriffe vollständiger europäischer Superiorität und geradezu animalischer amerikanischer Inferiorität übersetzt. In 
seiner Deutung des globalgeschichtlichen Ereignisses der sogenannten Entdeckung Amerikas war all dies schon in nuce enthalten.

Cornelius de Pauw wäre aber nicht Cornelius de Pauw, wenn er nicht auch auf dieser Ebene für sich einen kritischen Blick reklamieren würde, den Blick der aufklärerischen Kritik. Denn die absolute europäische Überlegenheit wird hinsichtlich der ersten Phase beschleunigter Globalisierung auf moralischer Ebene einer fundamentalen Kritik unterzogen. Vor dem Hintergrund der kolonialen Expansion des ausgehenden 15. und 16. Jahrhunderts warnt der Verfasser der Recherches philosophiques sur les Américains zugleich eindringlich vor den Konsequenzen jener zweiten, sich von Europa aus über den Globus ausbreitenden Expansionswelle, als deren kritischen Zeitgenossen und Zuschauer sich der holländische Abbé selbst portraitiert. Europa stehe im Begriff, unter der Anleitung von „Politiques“ und unter dem Beifall mancher „Philosophes“ die „Terres Australes“ machtpolitisch und wissenschaftlich in Besitz zu nehmen, ohne $\mathrm{zu}$ bedenken, wieviel Unglück man notwendig über die dort lebenden Völker bringen werde. ${ }^{17}$

Und de Pauw ging noch einen Schritt weiter! Denn für die Aufklärung einiger strittiger geographischer Fragen oder die überprüfbare Durchführung von Temperaturmessungen sei man in diesem aufgeklärten Jahrhundert jederzeit und ohne größeres Zögern bereit, die Zerstörung eines Teils unseres Erdkörpers, „la destruction d'une partie du globe“, in Kauf zu nehmen. ${ }^{18}$ So erscheint die Wissenschaft Europas in ihrer verselbständigten Eigenlogik als Impulsgeberin und Mittel europäischer Expansionspolitik zugleich. Die Wissenschaft wird als Teil (des Problems) der europäischen Expansion selbst erkannt; eine Einsicht, mit welcher der Holländer sicherlich als einer der Ersten den Finger in die Wunde europäischer Forschung legte.

Wie aber sollte man sich von deren Seite aus gegenüber außereuropäischen Gebieten in der zweiten Hälfte des 18. Jahrhunderts nun verhalten? De Pauw wusste, dass er in einer Zeit der Beschleunigung lebte, die wir heute als die zweite Phase beschleunigter Globalisierung benennen dürfen, und dass sein wohl bekanntestes Werk eine Reaktion auf diese globalgeschichtliche Entwicklung war. Einer derartigen, sich zeitgenössisch unstrittig beschleunigenden Entwicklung gelte es entgegenzutreten, so de Pauw: „Mettons des bornes à la fureur de tout envahir, pour tout connoître." 19 Setzen wir also dem Wüten, alles zu erobern, um alles zu wissen, deutliche Grenzen! Wissen ist in diesem Zusammenhang nicht nur Macht, sondern trägt - auch und gerade im Erkenntniswillen europäischer Wissen-

17 Ebda.

18 Ebda., Bd. 1, S. a4v.

19 Ebda., Bd. 2, S. $68 \mathrm{f}$. 
schaft - den Keim und die Macht von Zerstörung und Selbstzerstörung in sich. De Pauw macht klar: Bei der Eroberung der Welt hat die Wissenschaft gleich mehrfach, als Akteur und Vehikel, die Hand im Spiel. Und sie ist eine der grundlegenden Instanzen, die Macht über den Sinn verschaffen und ausüben. Dass de Pauws eigene Wissenschaftskonzeption eine solche auf empirische Erkenntnis abzielende Ausrichtung nicht benötigte, dürfte zur Genüge deutlich geworden sein.

Als Reaktion auf die Entwicklungen während der zweiten Phase beschleunigter Globalisierung betonte de Pauw zugleich, dass ein friedliches Zusammenleben unter den Bedingungen der Globalität stets von Europa aus gefährdet sei, konnte jede scheinbar lokale Auseinandersetzung doch einen Weltbrand entfachen, bei dem es dann kein Halten mehr gebe. Längst seien die politischen und wirtschaftlichen Interessengegensätze zwischen den Europäern gerade in den Kolonialgebieten so ausgeprägt, dass es nur eines Funkens bedürfe, um die ganze Welt in Flammen aufgehen zu sehen. So formulierte Cornelius de Pauw mit deutlich erhobenem Zeigefinger:

[...] ein Funken der Zwietracht, ausgelöst von wenigen Hektar Land in Kanada, setzt Europa in Flammen und in Brand; \& wenn Europa im Krieg ist, dann ist das ganze Universum mit dabei: alle Bereiche des Globus werden einer nach dem anderen wie von einer elektrischen Gewalt geschüttelt: Man hat die Bühne für die Massaker und das Hinschlachten von Canton bis nach Archangelsk vergrößert; von Buenos Aires bis nach Quebec. Da der Handel der Europäer die verschiedenen Teile der Welt mit derselben Kette auf intime Weise aneinander gefesselt hat, werden sie gleichermaßen in diese Revolutionen \& die Wechselfälle von Angriff \& Verteidigung geworfen, ohne dass sich Asien hierzu neutral stellte, wenn sich einige Händler in Amerika wegen Biberfellen oder Holz aus Campeche in die Wolle bekommen. ${ }^{20}$

Dieselbe Kette („une même chaîne“) verbindet die Welt und bindet sie mit all ihren Teilen als Fessel auf Gedeih und Verderb zusammen. Lokale Auseinandersetzungen sowie Konflikte im Welthandel konnten unversehens zu militärischen Konfrontationen eskalieren, die man - wie etwa mit Blick auf den Siebenjährigen Krieg (1756-1763) - mit Fug und Recht als Weltkriege bezeichnen darf. Und seien wir einmal ehrlich: Haben wir aus diesen historischen Erfahrungen wirklich etwas gelernt? Haben wir für das 21. Jahrhundert internationale Strategien entwickelt, um irgendwelche Handelsunstimmigkeiten zu entschärfen? Können die Handelskonflikte etwa zwischen den USA und China nicht unversehens zu Handelskriegen ausarten und schließlich in militärische Auseinandersetzungen einmünden, die weit über das Südchinesische Meer hinausgehen? Die Antwort auf derartige Fragen ist ein klares Nein!

20 Ebda., Bd. 1, S. 90. 
Nach der Veröffentlichung des von de Pauw in vielerlei Hinsicht noch zugespitzten zweiten Bandes der Recherches philosophiques sur les Américains setzte zunächst in Berlin, rasch aber auch in verschiedenen Ländern Europas und vor allem in Übersee eine heftige Auseinandersetzung ein, deren erste Phase man mit guten Gründen als die Berliner Debatte um die Neue Welt bezeichnen kann. ${ }^{21}$ Denn rasch trat Antoine-Joseph Pernety, der als ehemaliger französischer Benediktiner und Schiffskaplan auf Bougainvilles 1763 durchgeführter Reise auf die Malwinen die Protektion Friedrichs II. und eine Anstellung beim „Roi philosophe“22 als Bibliothekar erhalten hatte, in einem Vortrag vor der Berliner Akademie am 7. September 1769 vehement gegen die Thesen des Niederländers auf. Er veröffentlichte gleich im Folgejahr seine Dissertation sur l'Amérique et les Américains, contre les Recherches philosophiques de Mr. de $P^{* * *} .{ }^{23}$ Damit hatte ein Disput begonnen, dessen Folgen weit über die Grenzen Berlins, Preußens und Europas hinaus reichten und zugleich aufzeigten, dass die Aufklärung kein Privileg einiger weniger europäischer Länder war. Denn diese Debatte beleuchtete mit aller wünschenswerten Deutlichkeit, dass die Aufklärung längst auch auf jenem Kontinent gepflegt und weiterentwickelt wurde, den Cornelius de Pauw - drücken wir uns edel aus - in so unvorteilhaftem Lichte erscheinen ließ.

Wir werden uns in der Folge noch ausführlich mit der Berliner Debatte um die Neue Welt auseinandersetzen. Doch soviel sei vorab schon gesagt: Die Schwäche von Pernetys Angriff auf de Pauw lag zweifellos darin, dass er sich an vielen Stellen darauf beschränkte, wortreich dessen Thesen einfach umzupolen, schlicht das Gegenteil zu behaupten. De Pauws Abwertung alles Amerikanischen setzte er folglich eine Idealisierung der indigenen Bevölkerung entgegen, die auch vor dem Rückgriff auf das beliebte europäische Heterostereotyp vom „,bon sauvage“, vom „edlen Wilden“ nicht haltmachte. Pernetys beständige Beteuerungen, das von ihm Geschilderte mit eigenen Augen gesehen zu haben, konnten folglich nur begrenzt überzeugen: Weder konnte die Berufung auf die Augenzeugenschaft eine höhere epistemologische Wertigkeit für sich im Wissenschaftssystem des 18. Jahrhunderts in Anspruch nehmen noch machte die Betonung des Vor-Ort-gewesen-Seins die Ausführungen des nach Amerika gereisten Kontrahenten glaubwürdiger.

21 Vgl. hierzu die beiden Potsdamer Bände von Bernaschina, Vicente / Kraft, Tobias / Kraume, Anne (Hg.): Globalisierung in Zeiten der Aufklärung. Texte und Kontexte zur „Berliner Debatte“ um die Neue Welt (17./18. Jh.). 2 Bde. Frankfurt am Main - Bern - New York: Peter Lang Edition 2015.

22 Vgl. hierzu auch Fontius, Martin: Der Ort des „Roi philosophe“ in der Aufklärung. In (ders., Hg.): Friedrich II. und die europäische Aufklärung. Berlin: Duncker \& Humblot 1999, S. 9-27.

23 Vgl. hierzu Gerbi, Antonello: La Disputa del Nuovo Mondo, S. 120-125. 
Kein Wunder also, dass es de Pauw gelang, dadurch Kapital aus der anhebenden Polemik zu schlagen, dass er Pernetys Dissertation großzügig noch 1770 selbst in eine dreibändige Neuausgabe aufnahm und mit einem wohlkalkulierten Gegenangriff verband. Gewiss darf man bei Pernety „elements of a modern ethnological attitude“ ${ }^{24}$ erkennen, zu denen man sicherlich „the critique of Eurocentrism; the importance of gathering data in the field and verifying sources; the recognition of the cultural diversity of the Other“ ${ }^{25}$ rechnen kann. Doch blieb seine Argumentationsweise doch allzu sehr an die von de Pauw ins Feld geführten Thesen gebunden, die der Bibliothekar zumeist nur mit anderen Vorzeichen versah; und es half ihm auch wenig, sich (mit Verweis auf seine Reise an der Seite Bougainvilles in die Neue Welt) als kenntnisreicher Reisender zu präsentieren, während sein Kontrahent bekanntlich Europa nie verlassen hatte.

Eine mit allen Sinnen geführte Beschäftigung mit Amerika zählte in dieser Debatte wenig: „A beau mentir qui vient de loin.“ In der Berliner Debatte, in die Friedrich II. nach heutigem Kenntnisstand nicht direkt eingriff und an der er seine Freude gehabt haben dürfte, behielt Cornelius de Pauw souverän die Oberhand. Er vermochte mehr denn je öffentlichkeitswirksam zu behaupten, die kultivierten Völker Europas seien den „barbares de l’Amérique, qui ne savent ni lire, ni écrire, ni compter au-delà de leurs doigts“, ${ }^{26}$ unendlich überlegen. Denn diese ,Indianer“ konnten weder lesen noch schreiben noch über die Zahl ihrer Finger hinaus zählen: Dabei blieb de Pauw, mochte sein Kontrahent auch das Gegenteil behaupten.

Grundsätzliche und weit über den Horizont Pernetys hinausgehende Ein- und Widersprüche gegen Cornelius de Pauws Thesen ließen noch im 18. Jahrhundert jedoch nicht lange auf sich warten. ${ }^{27}$ Wir hatten bereits gesehen, dass Francisco Javier Clavijero den Thesen de Pauws in breiter Vielfalt amerikanische Quellen einschließlich der Bilderhandschriften und anderer indigener Dokumente entgegenstellte. Zugleich trieb der neuspanische Jesuit eine Konstruktion der amerikanischen Vergangenheit voran, die als - im besten Sinne - Findung und Erfindung einer anderen Herkunft auch eine andere Zukunft für seine amerikanische Heimat ermöglichen sollte. Die präkolumbischen Kulturen erschienen hier nicht länger

24 Mannucci, Erica Joy: The savage and the civilised: observations on a dispute between an enlightened writer and an illuminist. In: Studies on Voltaire and the Eighteenth Century (Oxford) 303 (1992), S. 384.

25 Ebda.

26 Pauw, Cornelius de: Recherches philosophiques sur les Américains, Berliner Ausgabe 1770, Bd. 3, S. 7.

27 Vgl. hierzu ausführlich Ette, Ottmar: Réflexions européennes sur deux phases de mondialisation accélérée chez Cornelius de Pauw, Georg Forster, Guillaume-Thomas Raynal et Alexandre de Humboldt. In: Bancarel, Gilles (Hg.): Raynal et ses réseaux. Textes réunis et présentés par Gilles Bancarel. Paris: Honoré Champion Editeur 2011, S. 183-225. 
als vernachlässigbare Randerscheinungen der Menschheitsgeschichte, sondern stellten sich selbstbewusst - wie wir bereits sahen - als amerikanische Antike einer europäischen gegenüber. Als Barbaren aber durften nun nicht mehr die inkriminierten Indianer de Pauws, sondern jene Konquistadoren gelten, die über die Kulturen des ,antiken“ Amerika hereingebrochen waren.

Mit dem neuspanischen Jesuiten trat die Berliner Debatte um die Neue Welt in einen weit größeren Zusammenhang ein und öffnete sich zu einer Diskussionsplattform. An ihr nahmen neben Clavijero nicht nur de Pauw und Pernety, Raynal und Robertson, sondern auch der neuspanische Dominikaner Servando Teresa de Mier, „Le Philosophe la Douceur“ alias Zaccaria de Pazzi de Bonneville, ${ }^{28}$ Giovanni Rinaldo Carli, Delisle de Sales, Drouin de Bercy, George Washington und viele andere teil. Dabei ging es - neben der Frage, wie die Gewichte in einer Aufklärung zwischen zwei Welten künftig verteilt sein würden - im Kern um die Problematik, auf welcher Seite des Atlantik die Macht über den Sinn der Geschichte der Neuen Welt liege. Es wurde zudem darüber debattiert, ob man diesen Sinn allein von einem Universum der Texte aus - und damit ohne ein sinnliches Erleben Amerikas - bestimmen könne.

War es da ein Zufall, dass mit der Berliner Debatte im Jahr 1769 die eigentliche ,heiße Phase' des internationalen Disputs um die Neue Welt ausgerechnet in der gegenüber Madrid und Lissabon, vor allem aber Paris, Amsterdam und London eher provinziell wirkenden Hauptstadt Preußens begann? Gewiss war mit Friedrich II. eine Persönlichkeit König in Preußen geworden, die bereits wenige Wochen nach der Thronbesteigung mit dem Überfall auf Schlesien im Dezember 1740 keinerlei Zweifel daran aufkommen ließ, für das Konzert der Großmächte eine neue Partitur schreiben zu wollen und diese auch international aufzuführen. Doch war Preußen in der zweiten Phase beschleunigter Globalisierung kein Global Player und besaß keine überseeischen Besitzungen, genauer: Das territorial zerrissene Königreich war keine Kolonialmacht mehr. Warum entbrannte also gerade in Berlin dieser Disput?

Es gab in preußischen Landen durchaus eine Sensibilität für die koloniale Frage. Denn entgegen aller landläufigen Annahmen hatten Brandenburg und Preußen zuvor durchaus koloniale Aktivitäten entfaltet und versucht, sich ihren Anteil an der Expansion Europas sowie am lukrativen ,Kolonialgeschäft' zu sichern. Schon der Große Kurfürst hatte mit freilich wechselhaftem Glück und Geschick versucht, aus den einträglichen Wirtschaftsbeziehungen zwischen Alter und Neuer Welt Gewinne zu erzielen. Er setzte dabei auf den profitabelsten Teil dieser kolonialistischen Geschäftspraktiken: den Sklavenhandel.

28 Vgl. hierzu Zantop, Susanne: Colonial Fantasies. Conquest, Family, and Nation in Precolonial Germany, 1770-1870. Durham - London: Duke University Press 1997, S. 47. 
Nicht umsonst hatte Friedrich Wilhelm I. (1640-1688) in Amsterdam studiert und aus nächster Nähe beobachten können, wie Seehandel und Kolonialpolitik auch ein kleines Land in die Rolle einer international führenden Handelsmacht katapultieren konnten. ${ }^{29} 1647$ schlug ein ehemaliger niederländischer Admiral, Arnoult Gijsels, als Berater des Kurfürsten vor, eine Handelskompanie unter brandenburgischer Führung und Flagge zu gründen. Parallel hierzu führte man Verhandlungen mit Dänemark über den Verkauf des dänischen Stützpunktes Tranquebar. $^{30}$ Nach mancherlei Rückschlägen war es erneut ein Niederländer, der Reeder Benjamin Raule, der Brandenburg beim Aufbau einer Flotte half und 1677 zum „Oberdirektor in Seesachen“ und später zum Minister für Seefahrt und die Kolonien ernannt wurde. ${ }^{31}$ Wir hatten bereits am Beispiel und Schicksal von Anton Wilhelm Amo gesehen, welch enorme Bedeutung gerade die Niederländer für den kolonialen Blick und die damit verbundenen Geschäfte im deutschen Sprachraum hatten, war der kleine Amo doch nicht umsonst den Herzögen von Wolfenbüttel als guten Geschäftspartnern von niederländischer Seite zum Geschenk gemacht worden.

Die ,Geschäftsidee‘ griff auch in Brandenburg: 1680 stachen zwei Expeditionen unter brandenburgischer Flagge in See. In unmittelbarer Nähe zu holländischen und britischen Niederlassungen entstand der erste Kolonialstützpunkt Brandenburgs in Afrika, die Niederlassung Großfriedrichsburg, die einen Küstenstreifen des heutigen Ghana von etwa fünfzig Kilometer Länge kontrollierte. Der zweiten brandenburgischen Flotte gelang es unterdessen, vor Ostende das spanische Schiff „Carolus Magnus“ aufzubringen und zu kapern, so dass es unter dem Namen „Markgraf von Brandenburg“ eine zweite Karriere als Flaggschiff der brandenburgischen Flotte erlebte. ${ }^{32}$ Dies war das übliche Verfahren, dessen sich auch die Piraten und Freibeuter in der Karibik bedienten, war der Schiffbau doch als solcher zu kostspielig und aufwendig.

Den ersten Kaperfahrten der Brandenburger in der Karibik folgte 1682 die Gründung der „Brandenburgisch-Afrikanischen Kompanie“, die stark mit Niederländern und zum Teil mit Hugenotten besetzt war und 1692 in die „Brandenburgisch-Africanische-Americanische Companie“ umbenannt wurde. Zum Haupthafen der brandenburgischen Flotte wurde vertraglich das ostfriesische Emden erklärt: Das kleine Brandenburg war zu einer Kolonialmacht aufgestiegen, die hoffnungs-

29 Vgl. hierzu Lennert, Gernot: Kolonisationsversuche Brandenburgs, Preußens und des Deutschen Reiches in der Karibik, S. 11.

30 Ebda.

31 Ebda., S. 12.

32 Ebda., S. 12 f. 
voll versuchte, möglichst hohe Gewinne mit Kolonialwaren, vor allem aber aus dem lukrativen Sklavenhandel einzustreichen und zu erwirtschaften.

Über diesen Teil der brandenburgischen, preußischen und deutschen Geschichte als Kolonialgeschichte ist bis heute in der Öffentlichkeit wenig bekannt. Ich kann an dieser Stelle unserer Vorlesung nur einige wenige Ausführungen machen, die für das Verständnis der sich anschließenden literarischen und künstlerischen Entwicklungen unbedingt notwendig sind. Die Hoffnungen auf Gewinne wie auf Machtzuwachs schienen sich für Brandenburg zunächst zu erfüllen. So steuerte bereits 1686 ein erstes brandenburgisches Schiff mit vierhundertfünfzig afrikanischen Sklaven aus Großfriedrichsburg die gemeinsam mit Dänemark genutzte Insel St. Thomas an. Zu dieser brandenburgischen Niederlassung in der Karibik zählten bald dreihundert Europäer und einige hundert schwarze Sklaven. Etwa dreißigtausend Sklaven wurden unter brandenburgischer Flagge und unmenschlichen Bedingungen von Afrika nach Westindien verschleppt, verschifft und verkauft. ${ }^{33}$

Auch wenn Kurfürst Friedrich III., der 1688 die Nachfolge des „Großen Kurfürsten“ antrat und seit 1701 als Friedrich I. den noch prekären Titel eines Königs in Preußen trug, die kolonialen Ambitionen und Aktivitäten seines Vorgängers fortzusetzen versuchte, versank die „Brandenburgisch-Africanisch-Americanische“ Companie doch in Schulden. Schließlich wurde sie von Friedrich Wilhelm I., der seit 1713 regierte, zu einem Zeitpunkt liquidiert, als das koloniale Geschäft im Konzert der europäischen Mächte vor der sich noch nicht abzeichnenden zweiten Phase beschleunigter Globalisierung als immer weniger attraktiv erschien. 1738 wurde das letzte Eigentum der Companie versteigert: ${ }^{34}$ Die Kolonialgeschichte Preußens war fürs Erste zu Ende.

Kaum zwei Jahre später bestieg Friedrich II. nach dem Tod des verhassten Vaters den preußischen Thron. Eine sechsundvierzig Jahre währende Regierungszeit begann, in deren Verlauf der König Preußen nach seiner Façon ummodelte und zweifellos - um es mit den Worten Richard von Weizsäckers anlässlich des zweihundertsten Todestages Friedrichs im Jahre 1986 zu sagen - ein „unsentimentales, charakterstarkes, reformbereites Gemeinwesen“35 zu schaffen, aber gewiss auch ein Land mit einer für lange Zeit unberechenbaren Großmachtpolitik als Erbe zu hinterlassen. Doch erst das neugegründete Deutsche Reich sollte in der dritten Phase beschleunigter Globalisierung wieder eine Kolonialpolitik im eigentlichen, im expansiven Sinne betreiben und mit der von Bismarck konzipierten berüchtig-

33 Vgl. hierzu eda., S. $16 \mathrm{f}$.

34 Ebda., S. 23.

35 Weizsäcker, Richard von: Friedrich der Große: Geschichte und Mythos. In (ders.): Demokratische Leidenschaft. Reden des Bundespräsidenten. Herausgegeben und eingeleitet von Eberhard Jäckel. Stuttgart: Deutsche Verlags-Anstalt 1994, S. 76. 
ten Berliner Afrika-Konferenz im Jahre 1884/85 ein deutliches Zeichen seiner erneuerten Machtansprüche setzen. Eine Großmachtpolitik begann, deren desaströse Folgen erst im 20. Jahrhundert in all ihren Ausmaßen sichtbar wurden.

Doch zurück ins Zeitalter der Aufklärung! Dass man bereits am preußischen Königshof Friedrichs II. bisweilen auch wieder von kolonialen Phantasien ${ }^{36}$ eingeholt werden mochte, wird man nicht mit Sicherheit ausschließen können, auch wenn man in der preußischen Hauptstadt anders als in London und Paris, den europäischen Metropolen der zweiten Phase beschleunigter Globalisierung, keine unmittelbaren kolonialen Eigeninteressen mehr verfolgen konnte. Der unberechenbare preußische Monarch diskutierte aber nicht nur in seiner Tafelrunde mit Voltaire, Casanova, Raynal und anderen über das, was sich als Weltpolitik gerade neu herauszukristallisieren begann, sondern legte sehr wohl ein nachhaltiges Interesse an jenem Denker der Globalität an den Tag, den wir in den zuvor angestellten Überlegungen bereits kennengelernt haben. Nicht umsonst erschienen dessen Schriften in den sechziger und siebziger Jahren auf Französisch in Berlin.

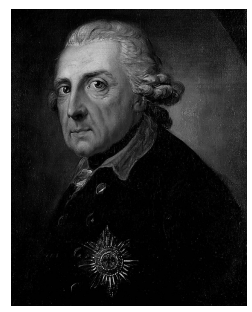

Abb. 30: Anton Graff: Friedrich II, König von Preußen (1712-1786).

So wurde de Pauw auch „Vorleser Friedrichs des Großen, in dessen Zirkeln die Anwesenheit des freigeistigen Abbé nun einmal ein unentbehrliches Dekorationsstück war“. ${ }^{37}$ Nicht nur während des ersten Aufenthalts de Pauws in Berlin und Potsdam zwischen 1767 und 1768, sondern auch während des zweiten zwischen 1775 und 1776 bemühte sich der charismatische Monarch um den Abbé und führte ihn als „neue Erwerbung“ in seine illustre Tafelrunde (die freilich schon bessere Tage gesehen hatte) ein. ${ }^{38}$ Wir wissen im Detail bislang wenig über die Beziehungen zwischen Friedrich II. und seinem Vorleser. Der Name de Pauws glänzt heute

36 Vgl. hierzu aus Sicht der Postcolonial Studies die Arbeit von Zantop, Susanne: Colonial Fantasies, insbes. S. 46-65.

37 Vgl. Beyerhaus, Gisbert: Abbé de Pauw und Friedrich der Große, eine Abrechnung mit Voltaire. In: Historische Zeitschrift (München - Berlin) 134 (1926), S. 467.

38 Ebda., S. 468. 
auch in den Standardwerken zu Friedrich dem Großen zumeist durch Abwesenheit. Dies scheint auch deshalb der Fall zu sein, weil man heute im deutschsprachigen Raum nichts mehr vom internationalen Renommee des Autors der Recherches philosophiques sur les Américains zu ahnen scheint. Doch darf man sicherlich davon ausgehen, dass der preußische König nicht unbeteiligt gewesen sein konnte an jener am 7. September 1769 entbrannten Berliner Debatte, die zwischen seinem Bibliothekar Pernety und seinem (ehemaligen) Vorleser de Pauw an jener Akademie der Wissenschaften ausbrach, die Friedrich 1744 als Förderer der Künste und Wissenschaften wiederbegründet hatte. Diese Debatte war einfach zu wichtig, als dass sie der Aufmerksamkeit des intellektuell wie künstlerisch hellwachen Herrschers entgangen sein konnte.

Umgekehrt kann auch von Cornelius de Pauw nicht unbemerkt geblieben sein, dass sich sein königlicher Gastgeber anderthalb Jahrzehnte zuvor in einem erst in neuerer Zeit wieder stärker von der Forschung in Augenschein genommenen Libretto mit einem amerikanischen Sujet beschäftigt hatte, das wir aus heutiger Sicht der ersten Phase beschleunigter Globalisierung zurechnen dürfen. So erscheint es wie ein ironisches Augenzwinkern, wenn der 1739 in Amsterdam geborene und noch nicht dreißigjährige Abbé in seinen Recherches philosophiques die Eroberung des Aztekenreiches durch die Spanier als den Raubzug von vierhundert Mördern und Banditen brandmarkt, ${ }^{39}$ die Hernán Cortés ebenso eigenmächtig wie habgierig um sich geschart habe. De Pauw kannte ,seinen` Friedrich und dessen Sichtweise auf die historischen Umstände der Eroberung Mexikos durch den spanischen Konquistador Hernán Cortés.

Sicherlich war Cornelius de Pauw auch nicht jene Passage des königlichen Librettisten unbekannt geblieben, in welcher sich der Aztekenherrscher Montezuma - in der italienischen Versübersetzung von Friedrichs Hofdichter Giuseppe Tagliazucchi $^{40}$ - über die Warnungen seines Generals Pilpatoè vor der Gefährlichkeit der heranrückenden Spanier hinwegsetzt:

Wie sehr, oh Himmel! kann dir deine Furcht

Den Muth benehmen ... Ist denn

39 Pauw, Cornelius de: Recherches philosophiques sur les Américains, Bd. 1, S. 58.

40 Vgl. hierzu Polzonetti, Pierpaolo: Political and Operatic Reforms of Frederick the Great. In (ders.): Italian Opera in the Age of the American Revolution. Cambridge: Cambridge University Press 2011, S. 109. Zur Rezeptionsgeschichte Montezumas bzw. Moctezumas im spanischen Theater vgl. u. a. Pérez-Amador Adam, Alberto: La constitución del modelo dramático del personaje de Moctezuma II en el teatro español de finales del siglo XVIII e inicios del siglo XIX. In: Floeck, Wilfried / Fritz, Sabine (Hg.): La representación de la Conquista en el teatro español desde la Ilustración hasta finales del franquismo. Hildesheim - Zürich - New York: Georg Olms Verlag 2009, S. 161-177. 


\begin{abstract}
Gegen dreihundert irrende Flüchtlinge, Die das Meer an dieses Ufer gespien hat, lidi?

Cieli! fin a qual segno il tuo timore

Avvilir ti può il core! Alla difesa

Del Messico sia d'uopo

D'un Esercito intero

Contro trecento fuggitivi erranti

Vomitati dal mare a questi lidi? ${ }^{41}$
\end{abstract} Mexico zu vertheidigen, ein ganzes Heer nöthig?

Dieser Stoff musste den Preußenherrscher sehr interessieren: Montezuma unterschätzt die sich aufbauende militärische Situation, obwohl er von seinen Gefolgsleuten über alle notwendigen Informationen verfügt. In seiner Menschlichkeit und Gutherzigkeit verkennt er die ihm und seinem Reiche drohende Gefahr. Denn diese dreihundert marodierenden Flüchtlinge, die bisweilen auch als Vagabunden erscheinen, ${ }^{42}$ werden aller Warnungen zum Trotz ins Herz von Montezumas Reich vorstoßen und sich mit aller Brutalität und Habgier an die Stelle des rechtmäßigen Herrschers der Azteken setzen. Zu Ehrenmännern wurden sie durch diese höchst riskante Machtergreifung - nicht nur in Friedrichs Augen - freilich keineswegs. Doch sehen wir uns diese machtpolitische Konstellation etwas genauer an!

Unsere kurze Zusammenfassung präsentiert in äußerster Verdichtung den Handlungsverlauf jener in jüngster Zeit wieder stärker ins öffentliche Bewusstsein gerückten Oper Montezuma, ${ }^{43}$ an deren Libretto Friedrich II. seit dem Spätsommer des Jahres 1753 gearbeitet hatte. ${ }^{44}$ Ist es ein Zufall, dass sie im Karneval des Jahres 1755 just an einem 6. Januar ihre Premiere im Königlichen Opernhaus Unter den Linden erlebte, an jenem Dreikönigstage also, an dem im Jahre 1492

41 Friedrich II. / Tagliazucchi, Giuseppe: Montezuma. Tragedia per musica. Da rappresentarsi nel Regio Teatro di Berlino per Ordine di Sua Maestà il Re nel Carnovale del MDCCLV. Berlino: Appresso Haude e Spener con licenza di Sua Maestà 1755, S. 32; dort auch die abgedruckte deutschsprachige Fassung, S. 33.

42 Vgl. hierzu Klüppelholz, Heinz: Die Eroberung Mexikos aus preußischer Sicht - Zum Libretto der Oper „Montezuma“ von Friedrich dem Großen. In: Gier, Albert (Hg.): Oper als Text: Romanistische Beiträge zur Libretto-Forschung. Heidelberg: Winter 1986, S. 82.

43 Aufführungen von Montezuma fanden in jüngster Zeit statt u. a. an der Oper Mannheim (26. März 2010), in der Hamburger Kulturfabrik Kampnagel (10. Juni 2010), in Mühlheim an der Ruhr (1. Juli 2010), im Schlosstheater zu Potsdam (21. Januar 2012) sowie eine konzertante Aufführung in der Staatsoper Unter den Linden (Ausweichquartier Schiller-Theater, 28. Januar 2012) statt.

44 Vgl. hierzu Henze-Döhring, Sabine: Friedrich der Große: Musiker und Monarch. München: Verlag C.H. Beck 2012, S. 85. 
die Katholischen Könige Fernando und Isabel mit ihrem feierlichen Einzug in Granada die Eroberung des Nasriden-Reiches abschlossen? Damit beendeten sie die jahrhundertelange Herrschaft der Araber auf der Iberischen Halbinsel und ließen die Reconquista in eine künftige Conquista von Ländern außerhalb Europas - im Blick lagen zunächst die maurischen Reiche südlich der Straße von Gibraltar - umschwenken.

Fest steht, dass sich der preußische Monarch von Anfang an der politischen Tragweite seines heute sicherlich bekanntesten Opernprojekts bewusst war, ja dass es ihm um eine möglichst effizient und nachhaltig $\mathrm{zu}$ vermittelnde politische Botschaft ging, wie er dies Francesco Algarotti schon früh in einem Schreiben wohl von Oktober 1753 mitteilte. ${ }^{45}$ Darin berichtete Friedrich dem engen Freund von seiner Arbeit am Libretto:

Es ist Montezuma. Ich habe dieses Sujet gewählt und passe es derzeit an. Sie fühlen wohl, dass ich mich für Montezuma interessieren werde, dass Cortés der Tyrann sein wird, und das man folglich in der Musik selbst ein Stückchen Speck auslegen kann gegen die Barbarei der k[atholischen] R[eligion]. Doch ich vergesse, dass Sie in einem Land der Inquisition sind; so entschuldigen Sie mich bitte, und ich hoffe, Sie bald in einem häretischen Lande wiederzusehen, wo die Oper selbst zur Reform der Sitten und zur Zerstörung des Aberglaubens dienen kann. ${ }^{46}$

In diesem Schreiben lässt der preußische Monarch keinen Zweifel an seiner politischen Interessenlage und an seiner Absicht erkennen, gegen die Barbarei der Spanier und gegen die Katholische Kirche ein (literarisches) Zeichen zu setzen. Dafür bot ihm die Kunst, dafür bot ihm gerade die Oper ein reich ausgestattetes Spielfeld in einem Land, das nicht der Inquisition unterlag und in dem in religiösen Dingen jeder nach seiner Façon selig werden konnte. Dass Friedrich in seiner geplanten Oper folglich auf die „religion catholique“, auf den Katholizismus und seine Unterdrückungsmaschinerie abzielt, ist von Beginn des Vorhabens an damit ebenso klar wie die Tatsache, dass es in seiner Oper Montezuma nicht weniger um die Frage der Macht als um die (Unter-) Scheidung zwischen Barbarei und Zivilisation gehen muss.

Dass er dies „en musique même“ - was man nicht, wie des Öfteren geschehen, mit ,selbst in der Musik“, sondern ,in der Musik selbst“ übersetzen sollte - zu tun gedenkt, wirft ein bezeichnendes Licht auf sein Verständnis von einem Zusammenwirken der Künste, welches auf ein Zusammenwirken der Sinne innerhalb eines hochpolitischen Zusammenhanges abzielt. Und diese Orchestrierung der Sinne ist,

45 Vgl. zu dieser Datierung ebda., S. 217.

46 Friedrich II.: Correspondance de Frédéric Second, Roi de Prusse, avec le Comte Algarotti. Pour servir de suite aux éditions des œuvres posthumes de ce Prince. Berlin: Chez George Gropius, Libraire 1887, S. 98. 
wie im Folgenden ausgeführt werden soll, im Medium der Oper mit der Frage nach der Macht auf intime, höchst sinnliche Weise verbunden. Denn Montezuma ist eine Oper über den guten wie den schlechten Gebrauch politischer Macht.

Am 16. April 1754 schreibt Friedrich II. aus Potsdam an seine Lieblingsschwester und erprobte musische Ratgeberin, die Markgräfin Wilhelmine von Bayreuth, und übermittelt ihr das in französischer Sprache verfasste Libretto mit den folgenden Worten:

Ich erlaube mir, Dir einen Mexikaner zu Füßen zu legen, der noch nicht ganz kultiviert ist. Ich habe ihm Französisch beigebracht; jetzt muss er Italienisch lernen. Ehe ich ihn aber dieser Mühe unterziehe, bitte ich Dich sehr, mir offen Deine Meinung zu sagen und ob Du glaubst, dass es sich lohnt. Die Mehrzahl der Arien soll kein Da capo erhalten; nur zwei Arien des Kaisers und zwei der Eupaforice sind dazu bestimmt. Ich weiß nicht, wie Du das Ganze, die Szenenfolge, den Dialog finden wirst und ob die Handlung interessant ist. Da aber die Sache nicht eilt, könnte ich das, woran Du etwas auszusetzen hast, leicht ändern. Die Wirkung des Stückes ließe sich sogar leicht erproben. Da Du eine wunderbare französische Theatertruppe hast, braucht sie es nur in Deinem Zimmer aufzuführen, auch wenn die Rollen nur abgelesen werden. ${ }^{47}$

In seinem Schreiben zeigt Friedrich durchaus gewisse Unsicherheiten gegenüber seiner künstlerischen Ratgeberin, auf deren Urteil er sehr viel gab. Doch von Beginn an setzt er auf die Wirkung des Wortes wie auf die der Musik, für deren Ausführung er bereits klare Vorgaben entwickelt hat - insbesondere die Abkehr von den Dacapo-Arien und die Hinwendung zur zweigliedrigen lyrischen Form der Kavatine. ${ }^{48}$ Wie würde die hochgeschätzte Schwester auf sein Ansinnen reagieren?

47 Brief von Friedrich II. an Markgräfin Wilhelmine von Bayreuth, 16. April 1754; ich danke Ruth Müller-Lichtenberg für die freundliche Übermittlung des Briefwechsels zwischen den beiden Geschwistern. Im Französisch Friedrichs des Großen lautet die Passage: „Ma tres chere Sœur. Je prens la liberté de metre a Vos pieds un Mexsiquain qui n'est pas encore toutafait de crassé je lui ai apris a parler français, il faut apresent quil aprene L'Italien, mais avans que de Lui donnér cette pene je vous suplie de me dire Naturelement Votre sentiment et si Vous Croyéz quil merite qu'on Lui donne ce soin; La plusparc des airs sont faits pour ne point etres repetéz il n'y a que deux airs de L'Empereur et deux d'eupaforis qui sont destinéz pour L'Etre, je ne sai Coment Vous trouveréz le tout ensemble L'enchainement des Scenes, Le Dialogue et L'Interet que j'aurois Voulû y faire regnér, mais Comme rien ne presseje pourai changér facilement ce que Vous y trouverais a redire; il seroit meme facile de jugér de L'Efet que le Spectacle peut produire, Vous avéz une admirable troupe françaisse il n'yauroit qu'a la lui faire representér dans Votre chambre qund meme chaqun ne ferait que Lire son role.“ GStA BPH Rep. 47 № 305-10, fol. $19 \mathrm{r}$.

48 Vgl. hierzu aus einer der Oper gegenüber künstlerisch recht kritischen Sicht Detering, Susanne: Friedrich II: Camouflage und Selbstverteidigung im Bild Montezumas. In (dies.): Kolumbus, Cortés, Montezuma: Die Entdeckung und Eroberung Lateinamerikas als literarisches Sujet in der Aufklärung und im 20. Jahrhundert. Weimar: Verlag und Datenbanken für Geistes- 
Nun, ihre Reaktion ließ nicht lange auf sich warten: In einem Schreiben an ihren Bruder zeigte sie sich am 25. April 1754 „entzückt“; 49 eine Entzückung, die später zu ihrem Vorhaben führte, das Werk im Markgräflichen Opernhaus zu Bayreuth aufzuführen. Die nicht selten enthusiastischen Kommentare Friedrichs gipfeln im nachfolgenden Briefwechsel schließlich in jenem Schreiben vom 11. Januar 1755, in welchem der König seiner Schwester selbstironisch, aber nicht ohne Begeisterung und fürstlichen Stolz von der ersten Aufführung des Montezuma an der Königlichen Oper Unter den Linden berichtete: „Der Dekorateur und der Kostümbildner haben den armseligen Textdichter aus der Affäre gezogen. Hauptsächlich zwei Pistolenschüsse haben außerordentlichen Beifall gefunden. Die Astrua hat die letzte Szene mit bewundernswürdigem Pathos gespielt und Graun hat sich in der Musik selber übertroffen.“50

Auf überzeugende Weise hat Ruth Müller-Lindenberg die von ihr konzipierte und im Januar 2012 eröffnete Ausstellung im Berliner Musikinstrumentenmuseum unter dem Titel „Friedrichs Montezuma“ ganz ins Zeichen all jener Sinne gestellt, die von Friedrich II. ganz bewusst angesprochen werden sollten. Montezuma ist eine machtpolitisch höchst reflektierte Oper und ein Zeugnis des Nachdenkens, ja bisweilen der Rechtfertigung eines Herrschers an der Macht. All dies galt es operntechnisch und künstlerisch umzusetzen. Denn nicht ohne Grund ist in den Briefen des Königs nicht allein von seinem französischen Libretto und dessen italienischer Übersetzung oder von der Musik seines Hofkapellmeisters Carl Heinrich Graun die Rede, sondern auch von den Stars der Aufführung. Zu ihnen zählten neben den hochbezahlten Kastraten die nicht geringer entlohnte Primadonna Giovanna Astrua, die Kostümbildner und Theaterarchitekten, allen voran Giuseppe Galli Bibiena, sowie all jene Künstler und Handwerker, die gleichsam für die ,special effects' verantwortlich zeichneten - von den Pistolenschüssen bis hin zur auf der Bühne zum Einsatz kommenden Pyrotechnik. Diese Oper sollte ein (machtpolitisches) Spektakel werden!

wissenschaften 1996, S. 196; aus musikwissenschaftlicher Sicht vgl. Henze-Döhring, Sabine: Friedrich der Große: Musiker und Monarch, S. $85 \mathrm{ff}$.

49 Brief von Wilhelmine von Bayreuth an Friedrich II. vom vom 25. April 1754. Im französischen Original: „J'ai eu L'honneur de recevoir votre Heros Mexiquain j'en ai étée enchantée. Les Sentiments, Les positions et la Conduite de la piece, touts cella dis je est exelant je faits ecrire les Rôles pour Les faire distribuer aux Comediens, et je conte que dans 3 semaines La piece sera jouée.“ GStA BPH Rep 46 W 17, Bd. III,5 (1754), fol. 11 r/v.

50 Brief von Friedrich II. an Wilhelmine von Bayreuth am 11. Januar 1755. Im französischen Original: „Le decorateur et le tailleur ont tiré Le pauvre Auteur d'aiffaire [!] surtout deux Mauvais Coups de pistolet ont etéz extremement aplaudi. L'astrua a joué la Derniere Scene avec un patetique admirable et Grauen s’est surpassé en Musique.“ GStA BPH Rep. 47 № 305-10, fol. 71 v. 
Die Macht des Zusammenwirkens all dieser Kräfte hatte der junge Kronprinz wohl erstmals bei seinem Besuch im Januar und Februar 1728 am königlich-kursächsischen Hofe in Dresden am eigenen Leibe erfahren. Dort hatte er die „schwindelnd machende Berührung mit einem höfischen Szenarium, das in seinem strahlenden Glanz, seiner verlockenden, spielerischen Leichtigkeit und der atemlosen Aufeinanderfolge von Komödien und Balletten, von Galatafeln und Redouten, Maskeraden und Feuerwerken als grandioses, die Sinne betörendes Blendwerk“ genossen. ${ }^{51}$ All dies sollte einen bleibenden Einfluss auf den künftigen preußischen Monarchen und seinen Wunsch haben, Dresden und Sachsen auch auf diesem Gebiet den Rang abzulaufen.

Ruth Müller-Lindenberg schreckte in ihrer wegweisenden Ausstellung nicht davor zurück, mit Hilfe eines Geruchsdesigners jenen Duft nachkomponieren zu lassen, der sich in einem geschlossenen Opernhaus aus den Kerzen und Lüstern, den verwendeten Parfums und dem Schweiß, aber auch dem Feuerwerk und dem Pulverdampf während der Vorstellung gebildet haben muss. Nicht umsonst gab sie ihrer Einführung in den Katalog zur Aufführung den Titel „Macht und Sinne?“ und stellte ihrer Ausstellung ein Zitat aus Julius Bernhard von Rohrs Einleitung zur Ceremoniel-Wissenschaft der großen Herren aus dem Jahre 1733 voran:

Sollen die Unterthanen die Majestät des Königs erkennen, so müssen sie begreiffen, dass bey ihm die höchste Gewalt und Macht sey, und demnach müssen sie ihre Handlungen dergestalt einrichten, damit sie Anlaß nehmen, seine Macht und Gewalt daraus zu erkennen. Der gemeine Mann, welcher bloß an den äusserlichen Sinnen hängt, und die Vernunfft wenig gebrauchet, kann sich nicht allein recht vorstellen, was die Majestät des Königs ist, aber durch die Dinge, so in die Augen fallen, und seine übrigen Sinnen rühren, bekommt er einen klaren Begriff von seiner Majestät, Macht und Gewalt. ${ }^{52}$

Die Prachtentfaltung in der Kunst zielte demnach auf die Machtentfaltung im Denken des ,gemeinen Mannes‘ beziehungsweise des preußischen Adels. Die Autonomie der Kunst sollte erst im nachfolgenden Jahrhundert ein deutlich wichtigeres Thema sein: Im Preußen Friedrichs II. war alles dem Staatsziel und der absoluten Herrschaft eines aufgeklärten Monarchen untergeordnet. Das Spektakel der Oper war in diesem Sinne ein Spektakel von Macht und Gewalt, das vor allem auf eines gerichtet war: beim Publikum eine möglichst große Wirkung zu erzielen.

In Friedrichs Montezuma geht es daher nicht nur auf der Inhaltsebene, sondern nicht weniger auf der des Ausdrucks um das, was die Sinne überwältigt, was

51 Vgl. hierzu Kunisch, Johannes: Friedrich der Große. Der König und seine Zeit. Mit 29 Abbildungen und 16 Karten. München: Deutscher Taschenbuch Verlag 22010, S. 22.

52 Rohr, Julius Bernhard von: Einleitung zur Ceremoniel-Wissenschaft der großen Herren, zit. nach Müller-Lindenberg, Ruth: Macht und Sinne? Zum Konzept der Ausstellung. (Einleitung in den noch unveröffentlichten Ausstellungskatalog 2012). 
sich der bloßen Vernunft entzieht, was nicht allein in einem Universum der Texte vom armen Textdichter entfaltet werden kann. Friedrich II. war sich dieser Tatsache sehr wohl bewusst, wie seine ironischen Anmerkungen im oben angeführten Brief andeuten. Die Pistolenschüsse auf offener Bühne, die Feuerwerke in einer gewagten Bühnenarchitektur, die exotischen Kostüme und aufwendigen Ausstattungen sind keinem „effet de réel“, sondern einem „effet de pouvoir“ verpflichtet, der kraft seiner Macht über die Sinne den Sinn der Macht ebenso kunstvoll wie gleichsam ,natürlich‘ unter die Haut zu bringen vermag. Unter den Händen des Königs geriet die Oper zum Spektakel der Macht.

Kein Zweifel: Wer Oper sagt, der sagt gewiss auch Macht - ganz im Sinne Friedrichs II., der schon im Jahr nach seinem Machtantritt den Grundstein seines großen Opernhauses legen ließ, das die Berliner noch heute erfreut! Das Opernhaus Unter den Linden war das erste der vielen großen Bauvorhaben Friedrichs, welche die Residenzstädte Berlin und Potsdam entscheidend gestalten sollten. Es demonstriert eindrucksvoll, wie der preußische König die Förderung der Künste mit der Förderung (und Reflexion) seiner eigenen Machtfülle zu verbinden wusste. Der reflektierte Einsatz von Machtmitteln ist das eigentliche Signum der Ära Friedrichs des Großen.

In welchem Verhältnis aber stehen Politik und Ästhetik? Die angestrebte Verwirrung der Sinne zielt folglich auf eine Verführung der Sinne, deren ästhetische Kraft nicht ohne Rückwirkungen auf das Verhältnis zur politischen Macht des Monarchen bleibt. Dies bedeutet keineswegs, dass damit die Vernunft weitgehend ausgeschaltet oder im Sinne der Ideen von Rohrs vollständig überwältigt wäre. Denn auch die Vernunft - nur eben nicht die „bloße“, die nackte Vernunft wird in das Spiel der Verwirrungen gezogen und mit Hilfe der Worte in Bewegung gesetzt, die wir im Libretto wie in einem Lesedrama isoliert betrachten können. Dies geschieht in Friedrichs Oper Montezuma gleich in der ersten Szene des ersten Aktes, die von Beginn an alles mit der Frage nach der Macht und ihrem gerechten, angemessenen Gebrauch verknüpft.

Dies war selbstverständlich keine Problematik, die sich allein im künstlerischen Bereich höchst dringlich präsentierte. Sie stand nicht weniger im Zentrum der politisch-philosophischen Schriften, die Friedrich II. zugerechnet werden. Nach seiner Lektüre von Machiavellis Il Principe teilte er in einem Brief vom 31. März 1738 an Voltaire bereits sein Vorhaben mit, dieses im Geist mittelalterlicher Fürstenspiegel verfasste Werk, das Friedrich in französischer Übersetzung las, sorgfältig zu widerlegen. ${ }^{53}$ Voltaire bestärkte den preußischen Kronprinzen in seinem Vorhaben und sprach davon, dieses Werk könne dereinst zum „Katechismus

53 Vgl. hierzu Kunisch, Johannes: Friedrich der Große. Der König und seine Zeit, S. 124. 
der Könige und ihrer Minister" werden. ${ }^{54}$ Wenn es auch nicht zum Katechismus der Könige wurde, so war es doch das Fingerspiel und vielleicht mehr noch die Etüde eines angehenden preußischen Königs.

Friedrich begann mit der Niederschrift wohl im Mai 1739 und schloss seine Gesamtkonzeption wahrscheinlich im November desselben Jahres ab, wobei er nachfolgend sein Werk noch mehrfach überarbeitete. Am 26. April schickte er seine Schrift an Voltaire in der Hoffnung, sein Text werde unter der Feder des französischen Philosophen sicherlich gewinnen. Es waren vertrauensvolle Jahre in der Korrespondenz zwischen dem preußischen Thronfolger und dem französischen Schriftsteller. Auf diese Weise entstanden zwei Fassungen, die unabhängig voneinander im Jahr 1740 in Den Haag veröffentlicht wurden: Zum einen Friedrichs Examen du Prince de Machiavel, avec des notes historiques et politiques, und zum anderen der Anti-Machiavel, ou Essai de critique sur le Prince de Machiavel, publié par Mr de Voltaire. ${ }^{55}$

Auch wenn an dieser Stelle die komplexe Entstehungsgeschichte dieser Schrift nicht weiter verfolgt werden kann, so ist für die Fragestellung unserer Vorlesung doch bedeutsam, dass Friedrich schon früh und gleich zu Beginn dieser zunächst anonym erschienenen „Réfutation du Prince de Machiavel“ seine Auffassung betonte, Machiavellis Il Principe sei „eins der gefährlichsten unter allen Büchern von Weltverbreitung“. ${ }^{56}$ Und mit derselben Stoßrichtung führte er kämpferisch aus: „Machiavell pflanzte den Keim des Verderbens in das staatliche Leben und unter-

54 Zit. nach ebda., S. 125.

55 Rasch erschienen weitere und erweiterte Ausgaben, wie etwa die im Folgejahr in Amsterdam veröffentlichte von Friedrich II.: Anti-Machiavel, ou Essai de critique sur le Prince de Machiavel, publié par Mr de Voltaire. Nouvelle Edition, où l'on a ajouté les variations de celle de Londres. Amsterdam: Chez Jaques La Caze 1741. Die komplexe Geschichte der Entstehung und Verbreitung dieser Schrift kann hier nicht dargestellt werden; vgl. hierzu die kritische Edition des Anti-Machiavel. Ed. par Werner Bahner et Helga Bergmann. Les Euvres Complètes de Voltaire. Bd. 19. Oxford: the Voltaire Foundation 1996. Dort findet sich auch der Text der französischen Ausgabe, die Friedrich konsultierte.

56 Hier zitiert nach der verbreiteten Fassung in Friedrich der Große: Antimachiavel. In (ders.): Historische, militärische und philosophische Schriften, Gedichte und Briefe. Mit Illustrationen von Adolph von Menzel. Herausgegeben von Gustav Berthold Volz. Köln: Anaconda Verlag 2006, S. 331. Das französische Original dieser Schrift wird zitiert nach Friedrich der Große: Anti-Machiavel ou Examen du Prince de Machiavel. Corrigé pour la plus grande partie d'après le manuscrit original de Frédéric II. Avec une introduction et des notes historiques. Hambourg : Chez Frédéric Perthes 1834, S. 4: „J'ai toujours regardé le Prince de Machiavel comme un des ouvrages les plus dangereux qui se soient répandus dans le monde.“ 
nahm es, die Vorschriften gesunder Sittlichkeit zu zerstören. “57 Anders als in den Schriften des Philosophen Spinoza hätten Machiavellis machttheoretische Überlegungen in Der Fürst nicht (nur) in die „Verirrungen des Denkens“ geführt, sondern eine (zweifellos fatale) „Bedeutung für das Leben selbst“ entfaltet. ${ }^{58}$ Daher der Plan des jungen Kronprinzen und angehenden Königs, die „Verteidigung der Menschlichkeit aufzunehmen wider ein Ungeheuer, das sie verderben will“ “. ${ }^{59}$ Eine Absage an die (Ausübung von) Macht, gar ihr Abgesang?

Keineswegs! Liest man Friedrichs Antimachiavel aus der Perspektive der anderthalb Jahrzehnte später entstandenen Oper und ihres Libretto, so kann kein Zweifel daran bestehen, dass Friedrichs Hernán Cortés die Verkörperung all jener Eigenschaften darstellt, die Machiavellis Fürsten auszeichnen: „Gier“, „Launen“, „Ehrgeiz“, „Tücke“, „Grausamkeit“ - kurzum: das Bild eines „politischen Ungeheuer[s]". ${ }^{60}$ Der junge Thronfolger dachte wesentlich komplexer, als ihm dies selbst ein Voltaire zugetraut haben dürfte. Noch in seinem auf den 26. Februar 1740 datierten und Voltaire zugeeigneten Gedicht Tod des Vaters wird Friedrich unmittelbar vor seiner Thronbesteigung ein weiteres Mal an „Machiavellis Frevelgeist“ erinnern und ein gekonntes Verstellungsspiel betreiben, als zögerte er, jetzt nach der Macht zu greifen. ${ }^{61}$ Gerade in den nicht selten gewalttätigen Auseinandersetzungen mit dem Vater hatte sich der Thronfolger jene „an Verschlagenheit grenzenden Verstellungskünste“ angeeignet, „mit denen er erst den Vater und

57 Friedrich der Große: Antimachiavel, S. 331. Im französischen Original: Friedrich der Große: Anti-Machiavel ou Examen du Prince de Machiavel, S. 4: „Machiavel corrompit la politique, et entreprit de détruire les préceptes de la saine morale.“

58 Friedrich der Große: Antimachiavel, S. 331. Im französischen Original: Friedrich der Große: Anti-Machiavel ou Examen du Prince de Machiavel, S. 3: „erreurs de spéculation“, „regardoient la pratique.“

59 Friedrich der Große: Antimachiavel, S. 331. Im französischen Original: Friedrich der Große: Anti-Machiavel ou Examen du Prince de Machiavel, S. 4: „J'ose prendre la défense de l'humanité contre un Monstre qui vent la détruire.“

60 Friedrich der Große: Antimachiavel, S. 332. Im französischen Original: Friedrich der Große: Anti-Machiavel ou Examen du Prince de Machiavel, S. 6: „[...] et quelle situation déplorable que celle des peuples, lorsqu'ils doivent tout craindre de l'abus du pouvoir souverain, lorsque leurs biens sont en proie à l'avarice de leur prince, leur liberté à ses caprices, leur repos à son ambition, leur sûreté à sa perfidie, et leur vie a sa cruautés. C'est lá le tableau d'un empire où régneroit un monstre politique tel quel Machiavel prétend le former.“

61 Friedrich der Große: Tod des Vaters. In (ders.): Historische, militärische und philosophische Schriften, Gedichte und Briefe, S. 545. Im französischen Original: Friedrich der Große: Correspondance de Frédéric avec Voltaire. Tome I. Depuis la première lettre de Frédéric jusqu'à son avénement. (8 Aout 1736-4 ou 5 Juin 1740). In: Preuss, Johann D (Hg.): Oeuvres de Frédéric le Grand. Tome XXI. Berlin : Imprimerie Royale (R. Decker) 1853, S. 398: „Dans ce terrain scabreux, raboteux, difficile / De machiavélisme infecté!“ 
dann die Kontrahenten im Konzert der Mächte hinters Licht zu führen verstand“ 62 Friedrich, von seinem Vater brutal unterdrückt, hatte nach der Hinrichtung seines Freundes Hans Hermann von Katte seine Lektion gelernt.

Würde Friedrich also nach der Macht greifen? Aber selbstverständlich, er zögerte nicht! Allerdings hatte er gegen das Abbild des Despotismus und der Tyrannei eindrucksvoll in seinem Antimachiavel ein anderes Herrscherbild gestellt: „So läuft es darauf hinaus, dass der Herrscher, weit entfernt, der unumschränkte Gebieter über seine Untertanen zu sein, nur ihr erster Diener ist, das Werkzeug ihres Glückes, wie jene das Werkzeug seines Ruhmes. “63 Der Philosoph auf dem Thron: Welche Rolle, welche Partitur hat Friedrich je mit größerer Hingabe, mit größerer Inbrunst gespielt?

Mit eben diesem Bild des dienenden Herrschers eröffnet Friedrich II. 1755 seine Oper Montezuma, in deren erster Szene der Aztekenherrscher voller Stolz auf eine für seine Untertanen wie für ihn selbst glückliche und ruhmreiche Herrschaft blicken kann. Alles ist für ihn noch vollkommen in der besten aller denkbaren Welten. Vor dem Hintergrund dreier großer Palmengänge in seinem kaiserlichen Garten wendet er sich an Tezeuco, einen Bediensteten aus seinem zahlreichen Gefolge:

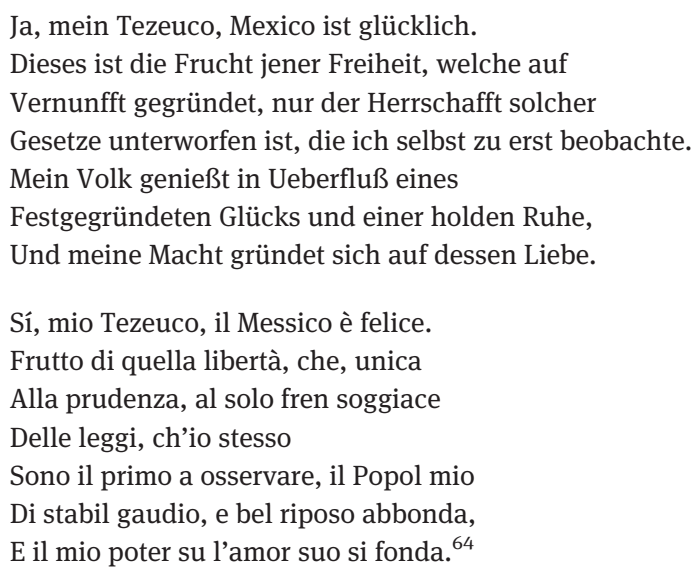

Mexikos Glück ist wie das seiner Bewohner dank eines vorausschauenden Herrschers in dessen eigenen Worten unermesslich. So präsentiert sich das Gemein-

62 Kunisch, Johannes: Friedrich der Große. Der König und seine Zeit, S. 25.

63 Friedrich der Große: Antimachiavel, S. 332. Im französischen Original: Friedrich der Große: Anti-Machiavel ou Examen du Prince de Machiavel, S. 10: „il se trouve que le souverain, bien loin d'être le maître absolu des peuples qui sont sous sa domination, n'en est en lui-même que le premier domestique.“

64 Montezuma. Tragedia per musica, S. $10 \mathrm{f}$. 
wesen der Mexica im ersten Rezitativ ihres Herrschers in offenkundiger Übereinstimmung mit jenem Idealbild, das der angehende preußische König für alle in der République des Lettres so hoffnungsvoll in seinem ersten politisch-philosophischen Traktat entworfen hatte. Sprach Friedrich dort nicht - als redete er von einem „contrat social“ - von jenen Völkern, „die einen Herrn über sich gesetzt haben lediglich, damit er ihnen Schirm und Schutz sei“, hätten sie sich ihm doch „nur unter dieser Bedingung unterworfen“? ${ }^{65}$

Friedrich aber spielt mit den Bildern der Macht und testet ihre Grenzen aus: Das Libretto, die Literatur, die Oper werden zu seiner Versuchsanordnung, zum Laboratorium seiner machtpolitischen Versuche. So war König Ferdinand von Aragonien für Machiavelli noch der Inbegriff des mit großer Geschicklichkeit vorgehenden Fürsten gewesen. Derselbe Ferdinand, der Granada eroberte und zusammen mit Königin Isabel den Machtimpuls Spaniens auf die Küsten der Neuen Welt richtete, wir nun einer harten aufklärerischen Kritik unterworfen, habe er doch die Religion „als Deckmantel“ für seine Pläne benutzt und für sein „heuchlerisches Tun den frommen Glauben des Volkes“ missbraucht. ${ }^{66}$

Damit aber wird jener europäische Monarch abgestraft, der nicht nur im Bunde mit der Kirche und der „Heiligen Inquisition“ - die Friedrich in seinem bereits angeführten Brief an Algarotti verhohnepiepelte - zu herrschen verstand, sondern die erste Phase beschleunigter Globalisierung politisch entscheidend prägte. So sind im Antimachiavel schon früh jene Feinde der Vernunft ausgemacht, für die man die Spanier im französisch geprägten 18. Jahrhundert ohne großes Federlesen hielt - wir haben dies in unserer Vorlesung bereits mehrfach und deutlich gesehen. Friedrich II. lag mit seinem Montezuma also ganz im Trend der Zeit und des anti-spanisch eingestellten Aufklärungszeitalters.

Spanien und die Katholische Kirche, beiderseits mit der „Santa Inquisición“ im Verbund: Damit werden im politisch-philosophischen Traktat früh schon jene allseits verhassten Störfaktoren für einen gerechteren Gang des Menschengeschlechts identifiziert, gegen welche Friedrichs Oper Montezuma ihr sinnenbetörendes Feuerwerk abzubrennen sucht. Hat nicht Cortés wie ein zweiter Ferdinand vor seinen Gräueltaten und Massakern an einer unschuldigen Bevölkerung in der siebten Szene des zweiten Akts noch versucht, sein schändliches Tun mit dem Hinweis auf die christliche Religion zu bemänteln, und die von ihm hingeschlachteten Mexica

65 Friedrich der Große: Antimachiavel, S. 334. Im französischen Original: Friedrich der Große: Anti-Machiavel ou Examen du Prince de Machiavel, S. 11: „qui se sont donné des souverains pour qu'ils les protègent“, „qui ne se sont soumis qu'à cette condition.“

66 Friedrich der Große: Antimachiavel, S. 337. Im französischen Original: Friedrich der Große: Anti-Machiavel ou Examen du Prince de Machiavel, S. 169: „un voile pour couvrir ses desseins“, „son hypocrisie la crédulité des peuples au profit de son ambition.“ 
unter Verweis auf ihre Menschenopfer als Barbaren bezeichnet? Und ist nicht vielmehr er selbst die Inkarnation menschlicher Barbarei?

\author{
Unser Gesetz will, dass wir die Götzen-Diener verabscheuen, \\ Welche barbarischen Göttern menschliche Opfer bringen. \\ Wir sind weniger darauf bedacht, Länder zu erobern, \\ Als vielmehr hier unsern Gott bekannt zu machen, \\ Und unter euch denjenigen vollkommenen \\ Gottes-Dienst zu stiften, der diesem Gotte angenehm ist. \\ Noi per legge abboriam l'empio Idolatra, \\ Ch'offre a barbari Dei vittime umane. \\ Più, che di far conquiste, \\ Cercham di farvi noto il nostro Dio, \\ E stabilir fra voi quella perfetta \\ Religion, che a questo Nume è accetta. ${ }^{67}$
}

Damit führt Friedrich ein weiteres zentrales Thema des Aufklärungszeitalters ein: die Frage nach den Grenzen zwischen Zivilisation und Barbarei. Doch wer die ,wahren 'Barbaren und wer die ,Zivilisierten ${ }^{688}$ in dieser Szenerie aus dem Jahre 1521 sind, liegt für das Publikum in der Lindenoper offen zutage. Wie sehr sich schon der junge Kronprinz mit Fragen und Herausforderungen des Globalisierungsprozesses nicht nur des 16. Jahrhunderts, sondern auch seiner eigenen Zeit beschäftigte, zeigt sich - neben vielen anderen Schriften aus seiner Feder - auch in verschiedenen Passagen seines Antimachiavel. Dort geht es etwa um die Strategien Frankreichs, die Handelswege von England und Holland, der „beiden blühendsten und reichsten Länder der Welt" ${ }^{69}{ }^{6}$ zu durchkreuzen und zum eigenen Vorteil zu nutzen. Auch wenn sich Preußen gerade aus dem transatlantischen Sklavenhandel zurückgezogen hatte: Friedrich wusste sehr wohl, wer sich an den Schätzen der Kolonien im transatlantischen Handel bereicherte.

Friedrich war sich der Tatsache bewusst, dass es längst nicht mehr Spanien und Portugal, sondern Holland sowie vor allem England und Frankreich waren, die mit zunehmender Dynamik im weltweiten Maßstab agierten und folglich eine wirkliche Großmachtpolitik entfesseln konnten, der er selbst nichts Gleichwertiges

67 Montezuma. Tragedia per musica, S. $70 \mathrm{f}$.

$68 \mathrm{Zu}$ dieser Konfliktlinie europäischer Reflexion über die Begegnung mit außereuropäischen Kulturen vgl. Bitterli, Urs: Die „Wilden“ und die „Zivilisierten“. Grundzüge einer Geistes- und Kulturgeschichte der europäisch-überseeischen Begegnung. München: C.H. Beck’sche Verlagsbuchhandlung 1976.

69 Friedrich der Große: Antimachiavel, S. 339. Im französischen Original: Friedrich der Große: Anti-Machiavel ou Examen du Prince de Machiavel, S. 174: „l'Angleterre et la Hollande, ces deux pays les plus beaux et les plus riches du monde.“ 
hätte entgegensetzen können. Die globale Dimension dieses Handelns erschien ihm im Bereich des Handels zweifellos am vielversprechendsten, ohne dass er jedoch aus dem, was noch im 18. Jahrhundert als Welthandel bezeichnet zu werden begann, eine Epoche des Weltfriedens heraufziehen sah. Sein Montezuma situiert sich nicht zufällig zu Beginn einer Epoche, die wir als die zweite Phase beschleunigter Globalisierung benennen dürfen.

Dem angehenden Monarchen waren sicherlich die kolonialen Aktivitäten Brandenburgs und Preußens bestens bekannt, waren die letzten Reste der ehemaligen Kompanie des preußischen Überseehandels - wie wir sahen - doch erst ein Jahr vor der Veröffentlichung seines Antimachiavel aufgelöst und liquidiert worden. Erblickte er in einer möglichen Wiederbelebung kolonialer Aktivitäten Preußens ein eigenes Feld politischen Handelns?

Nichts in seinem Traktat, nichts in seiner Oper, nichts in der Friedrich gewidmeten Forschung deutet direkt darauf hin. Und doch ist es vor diesem Hintergrund bedeutsam zu begreifen, dass Friedrich II. künstlerische Beschäftigung mit der ersten Phase beschleunigter Globalisierung in seiner Oper Montezuma von einem eigenen Erfahrungs- und Erwartungshorizont geprägt ist, der ohne den Beginn der zweiten Phase beschleunigter Globalisierung nicht möglich gewesen wäre. Mit der Macht der Kunst spannt Friedrich einen transmedialen Experimentierraum aus, der keiner Mimesis konkreter historischer Machtfülle, wohl aber der ästhetischen Erprobung abstrakter Vorstellungen von Macht im weltweiten Maßstab dient.

Friedrichs Oper Montezuma ist auf intime Weise mit seinen politisch-philosophischen Schriften verbunden. Man darf das Rezitativ unmittelbar vor der ersten Arie des Montezuma als eine direkte Reminiszenz an den Antimachiavel begreifen, wenn der Aztekenherrscher auf die Lobeshymnen seines Bediensteten Tezeuco mit Wendungen antwortet, welche in buchstäblich verdichteter Form sein ideales Herrscherbild in den geschlossenen Raum einer preußischen Opernaufführung mit überklarer Helligkeit projizieren:

Ach, erhebe nicht eine schwache Tugend so sehr!

Thue ich ettwas anders, als meine Pflicht?

Ich verlange von dir, Freund! nicht Lobes-Erhebungen,

Sondern Rath: Ist es uns ein Verdienst,

Nicht ein Ungeheuer zu seyn?

Ach, verflucht sey jene grausame Staats-Kunst,

Welche in dem Blute der Unterthanen den Thron gründet.

Nein, für einen so unwürdigen Preiß

Könnte sich mein Hertz niemahls zu dem Besitz

Eines Thrones entschliessen.

Non innalzar cotanto

Sì deboli virtù. Faccio altro mai 
Che il mio dovere? Jo ti domando, amico,

Non lodi, ma consigli. E merito in noi

Il non essere un mostro? Eh pera questa

Politica crudele,

Che stabilisce il soglio

De' sudditi col sangue.

No, non saprebbe a prezzo così indegno

Questo mio cor deliberarsi al Regno. ${ }^{70}$

Der im Kriegshandwerk längst erfahrene Friedrich exerziert in seinem Montezuma die einzelnen Machttheorien und Machtpraktiken wie in einem Exerzier- oder besser Experimentierraum durch. Im zentralen Vers - „Ist es uns ein Verdienst, / Nicht ein Ungeheuer zu seyn?“ - wird in den Worten Montezumas jene antimachiavellistische Position des jungen Friedrich auf die Spitze getrieben, die den Herrscher nicht als absoluten Souverän, sondern als einen seinem sich ihm anvertrauenden Volk verpflichteten ,ersten Diener' des Staates begreift. Damit aber ist eine Position markiert, die es uns - wie auch die weitere Entwicklung der Oper deutlich belegt - weder erlaubt, die Figur Montezumas als die eines ,edlen Wilden' zu charakterisieren noch gleichsam identifikatorisch mit der historischen Gestalt des königlichen Librettisten in einer Art von Camouflage ${ }^{71}$ gleichzusetzen.

Friedrich zitiert sich gleichsam selbst, kommt auf seine früheren Schriften zurück. Wir haben es mit einem intratextuellen Verweissystem nicht selten ironischer Markierungen zu tun, das Montezuma - entgegen aller Behauptungen, die sich immer wieder in der Forschung finden ${ }^{72}$-- keinesfalls als „bon sauvage“ im Sinne des 18. Jahrhunderts idealisiert, sondern als eine Figura, ${ }^{73}$ als eine ästhetische Modellierung vorstellt, die im Verlauf der Oper einer kritischen Überprüfung unterzogen wird. Dass Friedrichs in Montezuma durchexerziertes Programm der Macht ein figurales war, steht außer Frage.

Mit guten Gründen ist wiederholt auf die Tatsache verwiesen worden, dass das Sujet der spanischen Conquista auf den europäischen Bühnen des 18. Jahr-

70 Montezuma. Tragedia per musica, S. 14 u. 16.

71 Vgl. hierzu Detering, Susanne: Friedrich II: Camouflage und Selbstverteidigung im Bild Montezumas, S. 203.

72 Vgl. jüngst Henze-Döhring, Sabine: Friedrich der Große: Musiker und Monarch, S. 87. Zur Problematik einer solchen Sichtweise vgl. auch Detering, Susanne: Friedrich II: Camouflage und Selbstverteidigung im Bild Montezumas, S. 199.

73 Vgl. zu diesem Begriff Auerbach, Erich: Figura. In (ders.): Gesammelte Aufsätze zur romanischen Philologie. Herausgegeben von Fritz Schalk und Gustav Konrad. Bern - München: Francke Verlag 1967, S. 55-92. Vgl. auch in neuester Zeit die auf Erich Auerbach zurückgreifende Potsdamer Habilitationsschrift von Gwozdz, Patricia: Ecce figura. Anatomie eines Konzepts in Konstellationen (1500-1900). 
hunderts bereits lange vor der Jahrhundertmitte Verwendung und im Bereich der Oper in Antonio Vivaldis Montesuma (1733) den wohl berühmtesten künstlerischmusikalischen Ausdruck fand. Doch bestand die Tradition der preußischen Hofoper seit 1747/48 gerade darin, ,überwiegend zu italienischsprachigen Opern umgewandelte französische Tragödien aufzuführen“, so dass man den Montezuma, der 1755 in der Oper Unter den Linden aufgeführt wurde, sehr wohl als einen „Fremdling“ bezeichnen darf, ${ }^{74}$ auch wenn er sich gattungskonform als „Tragedia per musica“ präsentierte. ${ }^{75}$

Dieser Fremdling freilich musste dem Publikum seltsam vertraut erscheinen, besaß er doch nichts von jener grobschlächtigen Wildheit, deren Archäologie Hayden White in seinem Essay über die Forms of Wildness erforschte und in einem „reappearing in the imagination of Western man - as the Wild Man, as the monster, and as the devil“76 erblickte. Als Wilder Mann und Ungeheuer aber erscheint gerade Montezuma als gebildeter und feinfühliger Aztekenkaiser nicht, wobei er zugleich das Verdienst weit von sich weist, selbst unter dem Druck einer grausamen Politik kein Ungeheuer zu werden. Montezuma bleibt seinem Charakter als Mensch mit Herzensgüte und voller Vertrauen in die Menschheit treu.

Den Wilden Mann, dessen archetypisches Bild die westliche Kulturgeschichte geradezu verfolgte und verfolgt, gibt vielmehr der Schüler Machiavellis, der mit List und Tücke, mit Mordlust und Massakern vorgehende Hernán Cortés, der zwar die Mexica als ungebildete Barbaren beschimpft, in seinem Reden wie in seinem Handeln aber stets als der eigentliche Barbar auftritt und gebrandmarkt wird. Von Anfang an ließ Friedrich II. an dieser stabilen Konstellation, wie das Schreiben von Oktober 1753 an Algarotti zeigte, keinen Zweifel. Friedrichs tyrannischer Cortés und nicht sein aufgeklärter Montezuma - ist es, der jenen „abyss into which mankind might fall“677 aufweist; jenen Abgrund also, der sich unter der dünnen Decke abendländischer Kultur nicht nur in Preußen so leicht zu öffnen vermag. Friedrich der Große wusste von diesem dünnen Firnis, der in einem letzten Anstrich mit den angenehm bunten Mustern der Zivilisation die darunter schlummernde Barbarei des Menschen überzieht.

74 Müller-Lindenberg, Ruth: Macht und Sinne? Zum Konzept der Ausstellung, S. 8. Zur Rezeptionsgeschichte aus der Perspektive Oswald Spenglers vgl. auch Birkenmaier, Anke: Versionen Montezumas. Lateinamerika in der historischen Imagination des 19. Jahrhunderts, S. $6 \mathrm{f}$.

75 Zur traditionalistischen Ausrichtung Friedrichs als Musiker wie als Komponist im Kontext bereits seiner Zeit als Kronprinz zu Preußen vgl. auch Kunisch, Johannes: Friedrich der Große. Der König und seine Zeit, S. 85.

76 White, Hayden: The Forms of Wildness: Archaeology of an Idea. In (ders.): Tropics of Discourse. Essays in Cultural Criticism. Baltimore - London: The Johns Hopkins University Press 1978, S. 180.

77 Ebda. 
So ist der auf die Berliner Bühne gebrachte Montezuma weder der üble Wilde noch der edle Wilde, ${ }^{78}$ sondern die Figura jenes im Antimachiavel gezeichneten Herrschers, die nun freilich im geschlossenen Raum der Oper wie in einem Experimentierraum öffentlich einem Härtetest unterworfen wird. Noch zu Beginn der Oper steht er in strahlendem Glanze da, weiß sich und sein Land in höchstem Maße glücklich und begreift sein eigenes Tun in vollständiger Übereinstimmung mit den Wünschen und Bedürfnissen seiner Untertanen, deren Willen er repräsentiert und als deren Diener er sich letztlich begreift. Mit dem Auftauchen des Hernán Cortés und seiner zu allem entschlossenen Soldateska aber erfolgt nun eine Überprüfung dieser Position und mehr noch eine Prüfung, deren Tragweite der Monarch - aller Warnungen zum Trotz - zu Beginn nicht überblickt und deren Tragik er am Ende schutzlos ausgeliefert ist. Er begreift erst, als es längst zu spät ist. Denn am Ende dieser Prüfung stehen der Zusammenbruch des Staates und die Hinrichtung des beim Volk zumindest zu Beginn so populären Herrschers.

So ließe sich die These wagen, dass in Friedrichs Libretto und in Carl Heinrich Grauns Oper der frühfridericianische Antimachiavel zugleich in Szene gesetzt, auf seine Widerstandsfähigkeit überprüft und schließlich als Herrscher nicht als überlebensfähig eingestuft wird. Des jungen Friedrich philosophische Ideen halten einem ,Härtetest' nicht stand, sobald sich der König nicht mehr im Bereich der Theorie, sondern der politischen Praxis bewegt. Zumindest könnte dies eine Art Rechtfertigung und Legitimation des eigenen politischen Handelns durch den an der Macht ,erfahrener' gewordenen Monarchen sein.

Mag Montezuma auch für das Berliner Publikum ein Fremdling gewesen sein: Die zu Beginn der Oper entworfene Figur des Herrschers war es nicht! In diesem transmedialen Transfer aus der Theorie des philosophisch-politischen Traktats in die inszenierte Praxis der realen Oper erfolgt eine fundamentale Transformation. Denn im Gewitter der Spezialeffekte im Bühnen- und Zuschauerraum wird die Tatsache grell beleuchtet, dass die Reinheit der Figura - wie Friedrich in seinem Antimachiavel festhielt - weder im „staatliche[n] Leben“ noch in der Bedeutung für das „Leben selbst“79 aufrechterhalten werden kann. Der Herrscher als Antimachiavel bricht unter dem Ansturm Machiavels in kürzester Zeit zusammen - und

78 Aus der ungeheuren Literatur zum „bon sauvage“ seien hier nur genannt Kohl, Karl-Heinz: Entzauberter Blick. Das Bild vom Guten Wilden und die Erfahrung der Zivilisation. Berlin Frankfurt am Main: Verlag Medusa 1981; sowie Duviols, Jean-Paul: Contribution des récits de voyage à la formation de l'image du „Bon Sauvage“ Américain. In: Les Amériques et l'Europe. Voyage - émigration - exil. Actes de la 3ème semaine latino-américaine. Toulouse: Université de Toulouse - Le Miral 1985, S. 27-36.

79 Friedrich der Große: Antimachiavel, S. 331. Im französischen Original: Friedrich der Große: Anti-Machiavel ou Examen du Prince de Machiavel, S. 3: „la politique“, „la pratique“. 
mit ihm sein gesamtes Staatswesen, das am Ende in Flammen aufgeht und aus der Weltgeschichte verschwindet. Dass Friedrich II. allerdings kurz nach seiner Thronbesteigung, als er sich seiner schlesischen Beute versichern wollte, bereits ungerührt zu kriegerischen Mitteln griff, mag zeigen, dass der noch junge Herrscher dem Principe von Beginn seiner Herrschaft an gar nicht ferne stand.

Friedrichs Montezuma versucht, seine zwar einerseits abstrakte, andererseits aber durchaus in der staatlichen Realität gemeinschaftlichen Lebens erprobte Überzeugung von der ethisch fundierten guten Regierung auch angesichts all jener skrupellosen Feinde aufrechtzuerhalten, die das Meer gleichsam ausgespuckt und in sein eigenes Land geworfen hat. Deren zahlenmäßige Unterlegenheit spielt dabei keine Rolle. Friedrichs Cortés erkennt sehr früh die Ethik guter Herrschaft als eine Schwäche des Systems und sucht, ihr mit aller Macht die Inszenierung eigener Macht entgegenzuhalten, die just auf die Verwirrung aller Sinne setzt. Er tut dies als guter Schüler Niccolò Machiavellis und mit durchschlagendem Erfolg.

So sind es die Pistolenschüsse, von denen Friedrich nicht von ungefähr in seinem Brief an Markgräfin Wilhelmine von Bayreuth kurz nach der Aufführung berichtet, die auf der Bühne abgefeuert auf jene listige Taktik der zu allem entschlossenen Spanier verweisen, zuallererst die Sinne ihrer Gegner zu verwirren. Sind erst die Sinne überwältigt, kann geradezu unbegrenzt Macht über die Azteken ausgeübt werden. Es sind die „special effects“ einer menschenverachtenden Bühnenkunst, die es den Spaniern erlauben, die von Furcht ergriffenen Azteken vor sich herzutreiben und Montezuma seinem fatalen Schicksal zuzuführen. Wer sich die Macht über die Sinne seiner Feinde wie seiner Untertanen verschafft, macht daraus jeden Sinn, den er der Geschichte seiner eigenen Macht verschaffen will: Vor diesem Hintergrund muss Montezuma untergehen. Friedrich II. aber wollte ein solches Schicksal nicht teilen.

Friedrichs Oper Montezuma führt dies ein ums andere Mal in aller Deutlichkeit vor Augen und bringt es zu Gehör. Im Vollbesitz rücksichtsloser Sicherheit macht der Spanier Narvès in der siebten Szene des ersten Aktes Montezuma klar, dass man bereits die ganze Welt erobert habe. Am Ende der fünften Szene des zweiten Aktes gehen die spanischen Truppen unter der Führung des Hernán Cortés unter den Klängen einer kriegerischen Symphonie mit aller Entschlossenheit und Brutalität gegen die Mexica vor, die bereits beim Klang der ersten für sie fremden, unbegreiflichen Schüsse jedweden Widerstand einstellen. Nicht seine Ehre und hehren Werte, wohl aber die Widerstandskraft des Montezuma sind gebrochen, erscheint er doch zu Beginn der unmittelbar folgenden sechsten Szene als „attonito, e spaventato“: ${ }^{80}$ Montezuma erkennt, dass

80 Montezuma. Tragedia per musica, S. 66. 
er einen fatalen Fehler begangen hat. Die Spanier hingegen wissen sich als Protagonisten einer Welt, deren Geschichte sie längst aus ihrer Sicht umzuschreiben begonnen haben. Und doch sind sie Barbaren und herrschen über ein Land, das sie nur auszuplündern und zu zerstören fähig sind. In einer Welt, die im Zeichen brutaler Gewaltausübung steht, genügt dies freilich.

Auch dies ist gewiss nicht das Herrscherbild, dem Friedrich II. sich verpflichtet fühlte. Und doch: Hatte er, der in seinem Antimachiavel so kurze Zeit vor seinem Machtantritt das Bild des edlen Fürsten malte, nicht schon nach wenigen Monaten auf dem Thron alle Regeln zwischenstaatlicher Vertragstreue und Reziprozität gebrochen? Mit List und Tücke, vor allem aber mit brutaler Waffengewalt hatte er Schlesien überfallen, um erfolgreich die reiche Provinz aus dem nach dem Tod Kaiser Karls VI. zeitweise führungsschwachen Habsburgerreich herauszubrechen und seinem eigenen Reich einzuverleiben? Gewiss wollte Friedrich nicht mit der Figur des Barbaren Cortés verwechselt werden; aber ein Montezuma, dessen Widerstand im schreckenerregenden Pulverdampf zu erliegen kommt und dessen Reich unter den Hufen der für die Mexica unbekannten Pferde zerfällt, wollte er ebenso wenig sein. Montezuma ist somit ein Stück über Macht im Medium der Macht; es macht daher nur Sinn, insofern es die Macht über die Sinne reflektiert. Und genau dies tut diese Oper aus der Feder eines aufgeklärten, aber gleichwohl absoluten Monarchen.

So führt die Oper Montezuma am 6. Januar 1755 gleichsam in ihrer ganz konkreten Aufführungspraxis vor, wie die Figura eines Herrschers, der sich allein abstrakten Werten verpflichtet weiß, im Angriffswirbel seiner Feinde untergehen muss und folglich alle medialen Gewalten dafür aufzubieten hat, die eigene Macht zu erhalten und wo möglich auszuweiten. Die Oper selbst, „l'opéra même“, ${ }^{81}$ wird daher für Friedrich II. zu einem mitreißenden Spektakel, zum - wie Algarotti ihm noch vor der Premiere von Montezuma schrieb - „spectacle magnifique du Nouveau monde“. ${ }^{82}$ In ihm verwirrt der preußische Monarch und Musiker die Sinne seiner Untertanen nicht nur mit Worten und Musik, sondern auch mit der exotischen Farbenpracht der Kostüme oder mit dem Pulverdampf seines Feuerwerks und kann sie folglich überwältigen. Dies ist der Sinn, dies sind die Sinne, welche die Neue Welt Friedrichs des Großen bestimmen!

Bereits die Zeitgenossen wussten es: Der preußische König hat sich nicht allein als Librettist betätigt und nicht nur den stärksten Einfluss auf die Musik wie auch (durch seine häufige Anwesenheit bei Proben) auf deren Ausführung genommen.

81 Friedrich II.: Correspondance de Frédéric Second, Roi de Prusse, avec le Comte Algarotti, S. 98.

82 Brief Algarottis vom 11. Januar 1754 aus Venedig an Friedrich II. In: Friedrich II.: Correspondance de Frédéric Second, Roi de Prusse, avec le Comte Algarotti, S. 100. 
Vielmehr entwarf er auch Bühnendekorationen und Kostüme, all das also, was in der Oper auf Wirkung und Zusammenwirken angelegt ist. Sicherlich hat dies mit Friedrichs großer Liebe zu den Künsten zu tun, aber auch mit kalter machtpolitischer Berechnung. Da er in alles wie ein Fürst und mehr noch wie ein Feldherr einzugreifen pflegte, sagte der englische Musikhistoriker Charles Burney nach einem Besuch im Jahr 1773 wohl zurecht vom preußischen Monarchen: „Der König hält im Opernhaus genauso Manneszucht wie in seinem Lager.“83 Die horrenden Kosten der Lindenoper standen zur vielberufenen ,Sparpolitik‘ des Königs nur in einem scheinbaren Widerspruch; denn „Macht äußerte sich nicht nur in einem schlagkräftigen Heer“ - die Oper war ein vortreffliches „Machtinstrument“84, dessen sich Friedrich auf hervorragende Weise zu bedienen wusste. Für diese Art der Machtausübung standen in der preußischen Staatskasse ausreichend Mittel zur Verfügung.

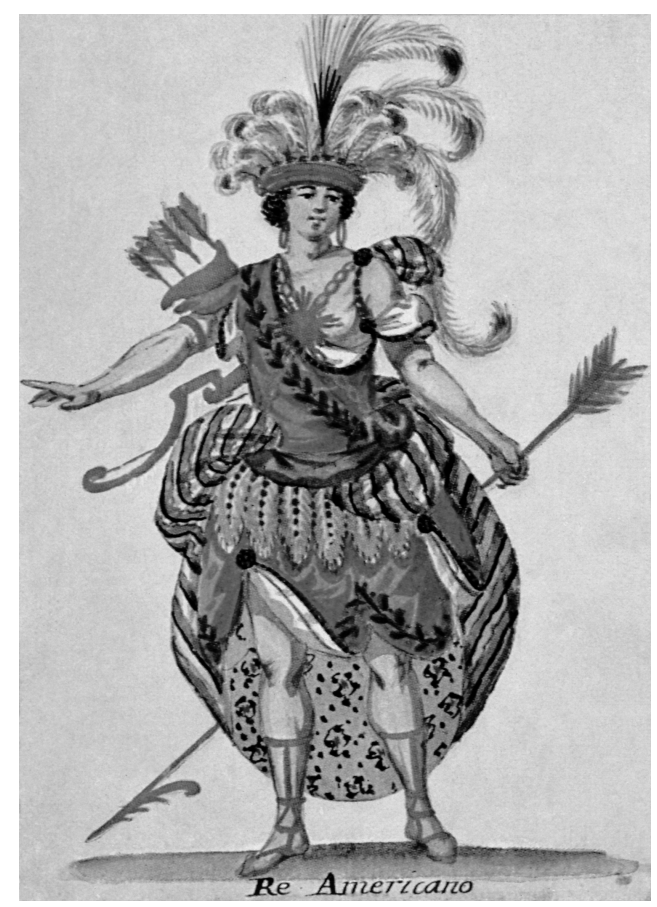

Abb. 31: Christian Gottlob Fechhelm (1723-1816): Kostüm für die Oper „Montezuma“. Musik: Carl Heinrich Graun, Text: Friedrich der Große.

83 Zit. nach Leithold, Norbert: Friedrich II. von Preußen. Ein kulturgeschichtliches und bebildertes Panorama von A bis Z. Frankfurt am Main: Eichborn (Die Andere Bibliothek) 2011, S. 327. 84 Leithold, Norbert: Friedrich II. von Preußen. Ein kulturgeschichtliches und bebildertes Panorama von $A$ bis $Z$, S. 327. 
Noch heute zeugen die von Christian Gottlob Fechhelm gearbeiteten Figurinen des mexikanischen Kaisers ${ }^{85}$ von der enormen Prachtentfaltung einer Ausstattung, die der preußische Monarch mit ungeheurem materiellen Aufwand und enormen Gagen für seine Opernstars ${ }^{86}$ wie für sein Orchester, seine Dekorateure und Bühnenarchitekten betrieb. ${ }^{87}$ Mit der Macht über die Sinne seiner Untertanen führte die Oper in ihrer sinnlich erfahrbaren Fülle selbst den Sinn der Macht vor, die sich im königlichen Librettisten leibhaftig verkörperte. Es ist ein Spektakel der Macht, das nicht die Macht als Spektakel, wohl aber den Sinn der Macht in der Macht über die Sinne zelebriert.

Lässt sich Friedrichs fürstliches Libretto und die Aufführung ,seiner` Oper in der Musik von Carl Heinrich Graun, der Theaterarchitektur von Giuseppe Galli Bibiena, den Arien von Giovanna Astrua und Hunderter weiterer Mitwirkender als Vorspiel jener Berliner Debatte um die Neue Welt begreifen, die seit Ausgang der sechziger Jahre des 18. Jahrhunderts in einer längst weltweiten République des Lettres die Gemüter erhitzte?

Die Antwort auf diese Frage kann nicht einfach sein, sondern wird differenziert ausfallen müssen. Denn Friedrich II. verlegte ganz entgegen der von ihm selbst protegierten preußischen Traditionen der Hofoper den Schauplatz zwar ins räumlich wie zeitlich weit entfernte Land der Azteken, tat dies aber nicht, um einen wie auch immer gearteten anthropologischen Disput über die Bewohner der Alten wie der Neuen Welt in Gang zu setzen. Dass sich Friedrich II. nur mit Mythen und Legenden rund um die Eroberung Mexikos beschäftigt habe, ist eine in der Forschung immer wiederkehrende Behauptung. ${ }^{88}$ Tatsächlich griff der preußische Monarch nachweislich auf die als historiographisches Standardwerk geltende Historia de la conquista de México von Antonio de Solís y Ribadeneyra von 1684 zurück. $^{89}$

Zwar entfaltete Friedrich aus dem Erleben einer Phase beschleunigter Globalisierung, in der die neuen Mächte der europäischen Expansion ihre eigene Überlegenheit gegenüber Spanien und Portugal ebenso auf der materiellen wie - dank Zuhilfenahme der „leyenda negra“ - auf der ethisch-moralischen Ebene lautstark

85 Vgl. hierzu Henze-Döhring, Sabine: Friedrich der Große, S. 89.

86 Vgl. hierzu Leithold, Norbert: Friedrich II. von Preußen. Ein kulturgeschichtliches und bebildertes Panorama von A bis Z, S. 327; dort finden sich auch genauere Angaben etwa für die Primadonna Astrua oder den Kastraten Salimbeni.

87 Ebda., S. 328 sowie Müller-Lindenberg, Ruth (Hg.): Katalog zur Ausstellung.

88 Vgl. etwa Detering, Susanne: Friedrich II: Camouflage und Selbstverteidigung im Bild Montezumas, S. 198.

89 Vgl. hierzu u. a. Klüppelholz, Heinz: Die Eroberung Mexikos aus preußischer Sicht - Zum Libretto der Oper „Montezuma“ von Friedrich dem Großen, S. 68-79. 
proklamierten, einen kritischen, ja vernichtenden Rückblick auf die Protagonisten der ersten Phase beschleunigter Globalisierung. Doch war es ihm dabei gewiss nicht um die programmatische Aufwertung außereuropäischer Kulturen zu tun, wie wir sie auf anthropologisch fundierter Basis in Preußen ein halbes Jahrhundert später im Werk Alexander von Humboldts sich entwickeln sehen, sondern um die Schaffung eines ästhetischen Erprobungsraums, in dem das historisch Vorgefundene wie das künstlerisch Erfundene einem unmittelbar sinnlichen Erleben zugeführt werden sollte. Friedrich war nicht an Fragen von Inferiorität und Superiorität innerhalb der kolonialen Asymmetrie transatlantischer Beziehungen interessiert. Die Oper als politische Demonstration von Macht wie als Demonstration politischer Macht lieferte und schuf vielmehr jenen Projektionsraum und Resonanzboden, mit deren Hilfe sich die Frage der Macht auch und gerade in einem weltweiten Maßstab stellen ließ. Wir werden uns erneut mit der Berliner Debatte um die Neue Welt beschäftigen müssen, um die Beziehung von Friedrich des Großen Oper zu den in der Debatte behandelten Themen und Fragen zu klären.

Spätestens seit der Abwicklung der Restbestände seiner überseeischen Handelskompanie war Preußen kein Protagonist innerhalb der um die Mitte des 18. Jahrhunderts wieder einsetzenden Phase beschleunigter Globalisierung mehr. Die Preußen hatten sozusagen den entscheidenden historischen Moment verpasst - man darf sagen: glücklicherweise! Vielleicht schuf gerade diese Distanz eine Möglichkeit, die Globalisierungsschübe umso besser zu analysieren und theoretisch zu beurteilen. Vielleicht war es gerade diese Distanz, welche Berlin zu Schauplatz und Bühne dieses Disputs um die Neue Welt machte.

So ist es sicherlich ebenfalls kein Zufall, dass in Potsdam und Berlin mit außereuropäischen Fragen vertraute Schriftsteller und Philosophen wie Maupertuis oder Voltaire, wie de Pauw, Pernety oder Raynal verkehrten. Gewiss spielte die Berliner Debatte in der Provinz. Am preußischen Hof wie im aufstrebenden Berlin entwickelte sich aber mit einer gewissen Kontinuität eine Beschäftigung mit außereuropäischen Fragestellungen, an die ein Alexander von Humboldt Jahrzehnte später anknüpfen konnte. Diese warf grundsätzliche Probleme jener Phasen beschleunigter Globalisierung auf, als deren wohl erster Theoretiker ein im provinziellen Berlin geborener Forscher, Gelehrter und Schriftsteller angesehen werden darf: eben der Jüngere der beiden Humboldt-Brüder. ${ }^{90}$

Alexander von Humboldts Schriften lassen sich wie eine späte, aber keinesfalls verspätete Antwort auf die zweite Phase beschleunigter Globalisierung begreifen. Dem gegenüber sind die in Potsdam und Berlin entstandenen Werke eines

90 Vgl. Ette, Ottmar: Alexander von Humboldt und die Globalisierung. Das Mobile des Wissens. Berlin: Suhrkamp Verlag 2019. 
Cornelius de Pauw oder eines Antoine-Joseph Pernety, aber auch der Opernentwurf von Friedrichs Montezuma komplexe und in sich widersprüchliche Reaktionen auf eine sich verändernde politische, ökonomische und kulturelle Situation, welche die zweite Hälfte des 18. Jahrhunderts gerade im transatlantischen Zusammenspiel charakterisierte. Montezuma ist als Oper Friedrichs II. sicherlich nicht Teil der an ,seiner` Akademie entbrannten Berliner Debatte; doch ist sie zugleich erheblich mehr als deren bloßes Vorspiel.

Diese „Tragedia per musica“ stellt die erst heute wieder unter veränderten Bedingungen neu zu beleuchtende Frage nach der Macht in ihrer globalen Dimension, wobei der preußische Monarch die Verwirrung der Sinne, die einst Hernán Cortés mit Pferdegetrampel und Artillerie zur Überwältigung der Mexica genutzt hatte, als Machtfaktor sinnlich erlebbar werden lässt. Diese Überwältigung war in der Menschheitsgeschichte stets ein Machtfaktor von allergrößter Wichtigkeit. Gewiss sind heute in dieser Funktion längst andere mediale Verbundsysteme an die Stelle der Oper getreten. Doch die von Friedrich in Szene gesetzte Überwältigungsstrategie demonstriert nicht nur die Macht, welche die Sinne über unser Denken und unser Leben ausüben, sondern auch die Notwendigkeit, eine die Sinne berauschende Gewalt stets mit der kritischen Frage nach dem Sinn der Macht zu konfrontieren, soll eine neue Welt ästhetisch vorgedacht und vorbereitet werden. Doch lassen wir Eupaforice, Montezumas Braut, jener furchtlosen indigenen Frau, die anders als alle anderen Figuren eine reine Erfindung Friedrichs ist, wie am Ende des zweiten Akts für heute das letzte Wort:

Der Himmel steht dem Kühnen bey,

Wenn er sich mit Muth bewaffnet,

Nicht erschrickt, und die Strenge des

Schicksals verachtet.

Seconda il Ciel l'audace,

Che di coraggio armato

Sprezza il rigor del Fato,

E paventar non $\mathrm{sa}^{91}$

91 Montezuma. Tragedia per musica, S. $102 \mathrm{f}$. 